UNIVERSITY OF GOTHENBURG

SCHOOL OF BUSINESS, ECONOMICS AND LAW

WORKING PAPERS IN ECONOMICS

No 478

\title{
Inflation Dynamics and Food Prices in Ethiopia
}

\author{
Dick Durevall \\ Josef L. Loening \\ Yohannes A. Birru
}

(November 2010)

Revised May 2013

ISSN 1403-2473 (print)

ISSN 1403-2465 (online) 


\section{Inflation dynamics and food prices in Ethiopia}

\section{May 2013}

DICK DUREVALL

(corresponding author) Department of Economics, University of Gothenburg and

Gothenburg Centre for Globalization and Development Dept. of Economics, PO Box

640, Gothenburg, Sweden tel. +46317861350

dick.durevall@economics.gu.se
JOSEF L. LOENING

Department of Economics University of Goettingen Platz der Goettinger Sieben 3 37073 Goettingen, Germany +49-551-39-7303

uwvw5@uni-goettingen.de
YOHANNES AYALEW. BIRRU

National Bank of Ethiopia Sudan Avenue, P.O. Box: 5550, Addis Ababa, Ethiopia yohannesayalew@nbe.gov.et 


\begin{abstract}
During the global food crisis, Ethiopia experienced an unprecedented increase in inflation, among the highest in Africa. Using monthly data over the past decade, we estimate models of inflation to identify the importance of the factors contributing to CPI inflation and three of its major components: cereal prices, food prices, and nonfood prices. Our main finding is that movements in international food and goods prices, measured in domestic currency, determined the long-run evolution of domestic prices. In the short run, agricultural supply shocks affected food inflation, causing large deviations from long-run price trends. Monetary policy seems to have accommodated price shocks, but money supply growth affected short-run non-food price inflation. Our results suggest that when analyzing inflation in developing economies with a large food share in consumer prices, world food prices and domestic agricultural production should be considered. Omitting these factors can lead to biased results and misguided policy decisions.
\end{abstract}

Key words: Commodity Prices; Ethiopia; Food Policy; Food Prices; Global Food Price Crisis; Monetary Policy 


\section{Introduction}

Global commodity prices have been on the rise. They reached record levels in 2008, declined during the financial crisis, but then rose sharply in 2010-2011. In mid2012, commodity food prices rose even further, surpassing the peak in $2008 .{ }^{1}$ As a result, several low-income countries are experiencing high price levels, trade deficits, and unstable macroeconomic environments. As there has been great variation in domestic food price developments across countries, our understanding about transmission patterns remains elusive (Baltzer, 2013). Yet high commodity prices, particularly for food, clearly have adverse effects on poverty in countries with large fractions of net food-buyers (Wodon and Zaman, 2010).

Several studies have attempted to address the underlying causes of the global price rise, typically identifying a combination of factors - ranging from long-term economic and demographic trends combined with short-term problems, such as bad weather, speculation, high oil prices, and export bans in a number of countries. ${ }^{2}$ At the same time, we know less about how world food prices affect domestic food prices in individual developing countries; particularly in Sub-Saharan Africa (see Minot, 2010).

One of the most affected countries is Ethiopia, which, with the exception of Zimbabwe and some small island economies, had the strongest acceleration in food price inflation in Sub-Saharan Africa (IMF, 2008a, 2008b; Minot, 2010). At the peak of the global food crisis, in July 2008, annual food price inflation surpassed 90 percent. This was a historically unprecedented rise, which began in 2006.

There is no consensus on why Ethiopia experienced such dramatic food price rises. The increase in inflation coincided with relatively favorable harvests, whereas in the past inflation had typically been associated with agricultural supply shocks due to droughts. World food price increases are believed to have small effects in Ethiopia because of the limited size of food imports, which amounts to about five percent of agricultural GDP. Minot (2010), for example, finds that out of the three staple food prices analyzed, one is affected by world market prices (wheat), but the transmission

\footnotetext{
${ }^{1}$ The price increases vary across commodities and data sources. The annual Commodity Food Price Index of the World Bank's Development Prospect Group rose by 13.2 percent in 2004, declined somewhat in 2005 , and then rose by $10.0,25.6$ and 34.2 percent in the following three years. In the middle of 2008, the index started to decline and by March 2009, it was at the same level as in mid-2007, which is almost twice as high as the average value in 1999-2003. It then rose by close to 50 percent, peaking in February 2011. The index declined slightly from early 2011 to June 2012 but rose sharply in July 2012, surpassing the previous peak (World Bank, 2012).

${ }^{2}$ Baffes and Hanioti (2010) provide a survey and extensive list of references.
} 
from world prices is negligible. Instead, the chief explanations have focused on domestic demand, expansionary monetary policy, a shift from food aid to cash transfers, and structural factors due to reforms and investments in infrastructure (Ahmed, 2007; IMF, 2008c; Rashid, 2010).

Nonetheless, few studies, if any, attempt to identify the relative importance of the factors driving inflation. The purpose of this article is to fill this gap of information by estimating a model of inflation for the period January 2000-December 2009, and by using data up to December 2012 for forecasting to check for robustness. ${ }^{3}$ We use general-to-specific modeling and estimate single-equation error correction models (ECMs) for the Consumer Price Index (CPI) and three of its major components: cereal, food and non-food prices. By developing measures of deviations from equilibrium in the money market, external sector, and agricultural market, we evaluate the impact on inflation of excess money supply, changes in food and non-food world prices, and domestic agricultural supply shocks. Agricultural markets can thus affect inflation both through the transmission of international food commodity prices and through changes in domestic food supply and demand. This approach can be viewed as a general (hybrid) model that embeds other models of inflation, allowing us to test various hypotheses, and account for the specific circumstances of developing economies with a large agricultural sector and a large share of food consumption expenditures.

One potential shortcoming of the single-equation approach is that we cannot measure indirect effects, for instance, how prices affect the exchange rate. Moreover, the equilibrium relationships are not estimated jointly, but are specified individually. Nonetheless, an important finding is that the parameters of the ECMs are empirically stable over the sample, indicating that the single-equation approach is adequate. ${ }^{4}$

Our results show that inflation in Ethiopia is closely associated with agriculture and food in the economy, and that the international food crisis had a strong impact on domestic food prices. The external sector largely determines inflation in the long run (about three to four years). Specifically, domestic food prices adjust to changes in world food prices, measured in local currency (birr), and non-food prices adjust to changes in world producer prices. There are large deviations from long-run

\footnotetext{
${ }^{3}$ Most of the data used for forecasting were not available when the models were developed.

${ }^{4}$ We also estimated systems of ECMs that included money and the exchange rate, and the values and standard errors of the parameters of interest only changed marginally. The results are available on request.
} 
equilibrium food prices, mainly due to the importance of the domestic market for agricultural products; domestic food supply shocks have a strong effect on inflation in the short run (about one to two years). These findings, however, do not imply that domestic and world food prices are always close to each other. They show that prices do not drift too far apart, which is consistent with observed price fluctuations of domestic prices between import and export parity bands. The evolution of money supply does not affect food prices directly, though money supply growth significantly affects non-food price inflation in the short run. It is possible that excess money supply affects the exchange rate, and thus inflation, which is not analyzed in this article. However, the birr-US dollar exchange rate is heavily managed by the central bank, so a possible link to money supply would be loose in the long run, and challenging to detect using empirical analysis. ${ }^{5}$ Nevertheless, a central finding of the article is that world food prices clearly had a strong impact on inflation during the study period.

A major contribution of the article is to takes into account specific circumstances of a developing country with a large agricultural sector. Most studies on inflation ignore domestic agriculture, and very few studies, if any, include international commodity markets in their analysis. In turn, studies on the transmission of world food prices to domestic food prices usually focus on individual prices and ignore the macroeconomic context. Finally, almost all previous studies on inflation in Africa model the CPI only, even though the weight of food in CPI is often very large, and the dynamics of food and non-food prices can differ considerably.

Another contribution of the paper is to show that it is possible to develop informative empirical models for an African country using monthly time series data for a relatively short period, provided there a reasonably well-defined policy regime. This challenges the view that major economic reforms throughout Africa, in combination with large external shocks and weak national statistical agencies, make it challenging to learn from empirical macro-models.

Section 2 gives a short description of Ethiopia's recent macroeconomic performance, and then outlines popular hypotheses of the causes of Ethiopia's inflation trajectory. Section 3 provides the theoretical framework, formulates the empirical model, and discusses how various hypotheses are tested. Section 4 describes and

\footnotetext{
${ }^{5}$ We tested if the rate of change of the birr-dollar exchange rate is affected by excess money supply, measured by the error correction term used in Table 4 . This was not the case. The results are available from the authors on request.
} 
analyzes the money market, external sector, and agricultural market, with the purpose of formulating explanatory variables for the inflation models. Section 5 develops the final models and carries out robustness checks, including forecasting. Section 6 discusses major findings, and Section 7 concludes.

\section{Inflation in Ethiopia: Background and previous studies}

\subsection{Economic performance and inflation}

In recent years, Ethiopia's economy has expanded rapidly: according to official data, GDP growth averaged 11.7 percent between 2004/05 and 2010/2011. Agriculture, which accounts for over 40 percent of GDP and nearly 85 percent of employment, grew by 8.4 percent. In spite of this, about 30 percent of Ethiopia's 84.7 million people lived below the official poverty line in 2011 (Government of Ethiopia, 2013), but it is likely that an even larger proportion have experienced extended periods of poverty due to shocks (Bigsten and Shimeles, 2008). The rise in food inflation, for instance, is likely to have increased urban poverty (Alem and Söderbom, 2012).

Historically, Ethiopia has not suffered from high inflation. The annual average was only 5.2 percent 1980/81-2003/04, and major inflationary episodes occurred only during conflict and drought. Annual average inflation reached a record of 18 percent during 1984/85 because of drought, 21 percent in 1991/92 at the peak of civil war, and again 16 percent during the 2003 drought.

Figures 1 and 2 depict the major trends in inflation during the current decade, January 1999-July 2010, by showing the annual growth rates of the CPI and its major components: food, cereals, house rents, construction, materials, energy and other nonfood prices. Table 1 gives a list of the CPI weights.

[Figures 1 and 2 here]

[Table 1 here]

The importance of fluctuations in food prices for the overall CPI is clearly visible in Figure 1. The deflation in 2001-2002 was due to good harvests and significant amounts of food aid inflows. There is a rapid increase in inflation induced by the 2003 drought, another increase around 2005, and an almost exponential price 
outburst in 2008. There was also a hike in non-food inflation during 2005-2007. Overall, it is evident that food and non-food inflation behave very differently, indicating that they should be analyzed separately.

As food accounts for 57 percent of total household consumption expenditure, low food and CPI inflation are associated with adequate rainfall and good crop harvests. However, this link seems to have been absent during 2004/05-2008/09, since food inflation continued to accelerate despite good weather and favorable agricultural production patterns. It is notable that annual food inflation, measured in simple growth rates, rose from 18.2 percent in June 2007 to a peak of 91.7 percent in July 2008. Food inflation then started to decline, and during the latter half of 2009 there was even deflation.

Figure 2 depicts food price inflation divided into its various components. Despite a short hike of spice inflation in 2007 , it is obvious that cereal price inflation accounts for most of the fluctuations in food prices. It is also the most important component of the food-price index; its weight in the CPI is close to 23 percent. The two graphs thus give an early indication of the key role played by food prices in general, and by cereal prices in particular, in Ethiopia's overall inflation dynamics.

\subsection{Review of studies on inflation in Ethiopia}

A few studies have emerged in the light of Ethiopia's food price crisis, drawing mainly on logical deductions and descriptive analysis. We subsequently review the most important ones.

The Ethiopian Development Research Institute (EDRI), a government thinktank, has put forward several hypotheses, summarized by Ahmed (2007). Increases in aggregate demand should a priori put pressure on demand for food, resulting in acceleration of food inflation. Yet, crop production has seen substantial growth during the period. Although this could be due to supply response, Ahmed (2007) concludes that it undermines the role of aggregate demand in explaining Ethiopia's recent food inflation since historically large harvests have led to lower food prices.

Changes in the structure of the economy, following a sustained development of the infrastructure network, are viewed as a potentially better explanation for the price increases. These include increased commercialization of crop production and reduced distress selling by peasants, equipped with better access to credit, storage facilities and 
marketing information system. As a result, farmers' bargaining position has improved, resulting in higher mark-ups and speculative storage.

Ahmed (2007) also lists various other domestic and external factors, including money supply and world commodity prices. In addition, housing shortages in urban areas and speculation have affected inflation, where a lack of regulation might have played a role in the surge in housing prices, particularly in Addis Ababa.

The International Monetary Fund (IMF, 2008b), on the other hand, suggests that inflation is being led by rapidly rising food prices. However, since inflation is higher in Ethiopia than in neighboring countries, domestic factors, including demand pressure and expectations should be important. Some supply-side factors may also explain part of the rise in food prices, such as reduced distress selling by farmers and the switch from food to cash aid. The Fund thus recommends addressing macroeconomic imbalances, and forcefully tightening monetary and fiscal policies. Rising global commodity prices may be important, but the transmission mechanism is not clear because the amount of non-aid food imports is relatively small. IMF (2008a) notes that there might be a process of convergence to world food prices driven by high food prices in neighboring countries, though there is a lack of empirical evidence.

Rashid (2010) also argues that the domestic food price increases were the result of general demand, except in 2007-2008 when cereal production was much smaller than shown by official agricultural statistics. General demand in turn, was driven by excess money supply; and accordingly, strict monetary policy brought inflation under control in 2008-2009.

Admassie (2013) reviews the political economy of food price changes in the country. He concludes that a combination of supply- and demand-side factors caused high price increases. However, food inflation was primarily caused by domestic factors, including speculative behavior of market participants, while developments in the international market had little impact.

Among the few empirical studies on Ethiopia is Ayalew Birru (2007). He develops a macroeconometric model for the National Bank of Ethiopia, the country's central bank, using annual data from 1970-2006. The chief claim is that supply shocks, inertia, and the consumer prices of major trading partners are among the most important determinants of inflation. Nevertheless, the use of annual data and the need to correct for major developments in Ethiopia's turbulent history limit the model's 
applicability, as does the fact that the analysis does not cover the period of rapid inflation, 2007-2008.

In the context of Ethiopia, two microeconometric studies are important. Osborne (2004) analyzes the role of news in the Ethiopian grain market. Although the focus is on generalizing the neoclassical storage model, it throws light on the microdeterminants of the inflation process because of the large weight of cereals in CPI. Osborne reports that there have been several occasions of sharp rises or falls in seasonal prices. For instance, in 1983/84, 1990/91 and 1993/94 maize prices rose by over 100 percent during periods of six months. She attributes these to the role of news of future harvests and forward-looking expectations. Thus, it is possible that the almost doubling of grain prices that took place between February and September 2008 is a similar phenomenon. Tadesse and Guttormsen (2011), using a rational expectations model and threshold regression, find evidence of speculative storage during periods of high prices over 1996-2006.

To conclude, while acknowledging the potential role of international prices, the implicit claim of the studies is that expansionary monetary policy has been the likely cause for high inflation, and world food prices have played a minor, or unclear, role. However, there is little empirical evidence of the relative importance of their contribution to inflation in Ethiopia.

\section{Modeling Inflation in an Agricultural Economy}

In this section we present an empirical inflation model that embeds different models of inflation. It allows us to test various hypotheses rather than imposing restrictions on the models, and can account for the specific circumstances of developing economies with a large agricultural sector. The Phillips curve and the quantity theory are the two traditional approaches used to model inflation, which we first review briefly.

The Phillips curve stipulates that high aggregate demand generates employment, which first leads to wage increases and later to rising prices. Although sometimes applied to Sub-Saharan Africa, as in Barnichon and Peiris (2008), it may not be an adequate approach for Ethiopia. Extensive self- and underemployment, large informal markets, and a low degree of labor-market organization all make the link between aggregate demand, unemployment and wage increases very weak or even 
non-existent. Moreover, there is a strong negative correlation between business cycles and inflation, since positive agricultural supply shocks increase GDP growth and lower inflation, and vice versa. Disentangling the Phillips curve effect, if it exists, is thus a challenging task since only annual GDP data is available.

Most studies on Sub-Saharan African economies therefore use the quantity theory and focus on the role of money supply and demand, assuming that inflation is due to excess money supply. Nowadays, foreign prices are often added to the models to account for imports or internationally traded goods. Some examples are: Blavy (2004) on Guinea; Moriyama (2008) on Sudan; Olubusoye and Oyaromade (2008) on Nigeria; and Klein and Kyei (2009) on Angola. Studies in this tradition usually neglect agricultural markets and food supply, even though food makes up more than half of the consumer basket. In fact, when food has a large weight in CPI, as in Ethiopia, food supply is bound to impact strongly on domestic inflation, at least in the short run. This seems to be the case in Kenya, Mali and Chad, as shown by Durevall and Ndung'u (2001), Diouf (2007) and Kinda (2011), respectively.

Following Juselius (1992) and Durevall (1998), we view inflation as mainly originating either from price adjustments in markets with excess demand or supply or from price adjustments due to import costs. The focus is on markets in three sectors: the monetary sector; the external sector, including the markets for tradable food and non-food products; and the domestic market for agricultural goods. Specifically, we postulate that changes in the domestic price level are affected by deviations from the long-run equilibrium in the money market and the external sector, represented by food and non-food products, giving three long-run relationships,

$$
\begin{aligned}
& m-p=\gamma_{0}+\gamma_{1} y+\gamma_{2} R \\
& p n f=e+w p-\tau_{1} \\
& p f=e+w f p-\tau_{2}
\end{aligned}
$$

where $m$ is the log of the money stock, $p$ is the log of the domestic price level, $y$ is the $\log$ of real output, $R$ is a vector of rates of returns on various assets and other sources of money demand, $p n f$ and $p f$ are the log of domestic non-food and food prices, $e$ is the $\log$ of the exchange rate, $w p$ and $w f p$ are the log of world non-food and food prices, and $\tau_{1}$ and $\tau_{2}$ are potential trends in the relative prices. 
Equilibrium in the monetary sector is spelled out in (1). Demand for real money is assumed to be increasing in $y$, where $\gamma_{1}=1$ for the quantity theory. In economies with liberalized and competitive financial markets, the relevant rates of returns are usually the interest rate paid on deposits and Treasury bills discount rates. However, in Ethiopia interest rates are unlikely to influence money demand due to heavy market distortions (Ayalew Birru, 2007). Earlier studies have mentioned various factors, such as returns to holding goods, foreign currency and coffee (Sterken, 2004; Ayalew Birru, 2007; IMF, 2008c).

Equations (2) and (3) can be viewed as the long-run equilibrium in the external markets for non-food and food products. Together they capture relative purchasing power parity. However, since Ethiopia has few exportable non-food goods, (2) primarily measures a relationship between prices of goods sold in the domestic market and imported consumer and intermediate goods. The link between domestic and world food prices, (3), is due to international trade or other factors. As described in Section 6, the relationship may in fact be complex because of the dominant role played by cereal prices, and Ethiopia's limited imports and exports of cereals.

As Figure 1 shows, there is a substantial difference in the behavior of the nonfood and food prices, motivating the use of price-specific formulations of the external sector. In the empirical analysis, domestic non-food prices and international producer prices are used when modeling non-food prices, and domestic and international food prices are used when modeling food prices. The trend terms in (2) and (3) are included because there might be trends in relative prices (real exchange rates) due to differences in productivity growth, changes in measurement or the use of a specific sample.

The domestic market for agricultural goods affects food inflation in the short run through supply shocks, i.e., the size of harvests relative to trend. The evolution of the level of agricultural production is unlikely to have a major impact on food prices during our study period, which is only eleven years. To model the agricultural market, we estimate a measure denoted the agricultural output gap (ag). It is obtained by calculating the trend in agricultural production with the Hodrick-Prescott filter, then removing the trend. There are other methods to estimate the gap, but the swings in agricultural production are so large that the choice probably does not matter much.

In the short run, several other factors might affect inflation as well. Thus, we also consider money growth, exchange rate changes, imported inflation, energy-price inflation and world fertilizer-price inflation. 
Ideally, we would analyze all the variables in a single system. However, because of the relatively small sample, we adopt an alternative strategy. We estimate the equations (1)-(3) separately first. Then, to examine the relative importance of the three relationships and the agricultural output gap in determining prices, we develop single-equation ECMs for each of the four price series. The specifications vary but a representative ECM is of the form:

$$
\begin{aligned}
\Delta p_{t}= & \sum_{i=1}^{k-1} \pi_{1 i} \Delta p_{t-i}+\sum_{i=1}^{k-1} \pi_{2 i} \Delta m_{t-i}+\sum_{i=1}^{k-1} \pi_{3 i} \Delta e_{t-i}+\sum_{i=0}^{k-1} \pi_{4 i} \Delta w f p_{t-i} \\
& +\sum_{i=0}^{k-1} \pi_{5 i} \Delta w p_{t-i}+\sum_{i=0}^{k-1} \pi_{6 i} \Delta e n e r g y_{t-i}+\pi_{7} a g_{t-1}+\alpha_{1}\left(m-p-\gamma_{1} y-\gamma_{2} R\right)_{t-1}(0) \\
& +\alpha_{2}\left(e+w p-p n f-\tau_{1}\right)_{t-1}+\alpha_{3}\left(e+w f p-p f-\tau_{2}\right)_{t-1}+\pi_{8} D_{t}+v_{t}
\end{aligned}
$$

where all variables are in logs, $\Delta$ is the first difference operator, $v_{\mathrm{t}}$ is a white noise process, $D_{t}$ is a vector of deterministic variables such as constant, seasonal dummies, and impulse dummies. To anticipate some of the findings: only one lag of agricultural output gap, ag, enters the model because the series is highly persistent. Moreover, output only enters in log-levels since monthly observations are not available. ${ }^{6}$

The long-run part of (4) consists of the three error correction terms, which allow for discrepancies between the log-level of the price and its potential determinants to impact on inflation the following period. Their coefficients, $\alpha_{1}, \alpha_{2}$ and $\alpha_{3}$, show the amount of disequilibrium (or strength of adjustment) transmitted in each period into the rate of inflation. The inclusion of variables in first differences and the agricultural output gap variable accounts for the short-run part of the model. Since (4) can be solved to get $p_{t}$ on the left-hand side, it determines both the log-level of the price, as well as the rate of inflation.

The estimation of single-equation ECMs implies some drawbacks, unless all explanatory variables are weakly exogenous. In the ideal case we would have tested for cointegration and weak exogeneity among all variables simultaneously with the Johansen approach, including the four price indexes. However, this is clearly not possible due to data limitation. The main consequence of not estimating a system is

\footnotetext{
${ }^{6}$ We interpolate annual GDP and cereal production to obtain the monthly observations for $y$ and $a g$. The series measure nicely the long-run trends in GDP and agricultural production, which are of primary interest for the analysis of the monetary sector and calculation of the agricultural output gap. However, the interpolation does not provide any information on monthly changes, so we do not include the monthly growth rates in our regressions.
} 
that we do not know what the feedback effects are, which affects the interpretation of our findings. There is also the question of endogeneity in the short-run part of the model. In equation (4) we condition on contemporaneous variables, which requires that the variables are weakly exogenous. In the empirical analysis we choose to only include lagged values of the potentially endogenous variables, the first difference of money and exchange rate. However, since we use monthly data the contemporaneous correlations are very low, so the final results are not affected by this choice. Furthermore, by checking the stability of the estimated coefficients we can, and do, obtain indirect support for the use of single-equation ECMs.

It is possible to view (4) as a general model that embeds other models of inflation within which we can test some of the hypotheses discussed in Section 2. A fundamental one is that excess money supply drives inflation. In the pure monetarist version, only variables entering the money-demand relationship should be significant. Since this implies assuming a closed economy, or a floating exchange rate and no imported intermediate goods, it is reasonable to allow imported inflation to influence domestic inflation or assume that the law of one price holds for tradable goods, while excess money supply affects non-tradable goods prices (Hanson, 1985; Jonsson, 2001). In the open economy version, a truly fixed exchange rate would make money supply endogenous. However, this case does not seem relevant for Ethiopia, which had a managed exchange rate during our study period.

An alternative interpretation is that inflation occurs when world prices rise or the exchange rate depreciates, while money supply is partly endogenous, as in Nell (2004), or that the monetary transmission mechanism mainly operates through the exchange rate channel, as Al-Mashat and Billmeier (2008) find to be the case in Egypt. Since capital flows are restricted in Ethiopia, the mechanism at work in the latter case would be through the impact of credit supply on imports and availability of foreign reserves, and not the traditional exchange rate channel where interest rates affect capital flows, which in turn affect the nominal exchange rate.

Another possibility is that domestic goods are made up of nontradables, exportables and importables, and that relative prices change due to an increase in export prices, for example. This leads to an improvement in terms of trade and disequilibrium in the external sector. As a result, either the nominal exchange rate has to appreciate, or the prices of nontradables have to increase, for equilibrium to be restored. Decreases in terms of trade, on the other hand, require a depreciation of the 
nominal exchange rate or a decline in domestic prices. It is quite possible that the consumer price rises in both cases. This occurs if the nominal exchange rate is not allowed to appreciate enough when terms of trade improve, and 'devaluations' push up prices through feedback effects when terms of trade deteriorate. Money supply would in this case be demand determined, or solely influence domestic prices through its effects on their proximate determinants (Dornbusch, 1980, chap. 6; Kamin, 1996).

Our specification also allows us to evaluate the importance of food prices for inflation in two ways. First, the specification of (4) makes it possible to estimate the impact of world food inflation on both Ethiopian food prices, as well as overall inflation. Second, the inclusion of the agricultural output gap allows domestic food supply to have an effect on inflation.

It is also possible to shed some light on the importance of structural change in agricultural markets, although a microeconomic analysis would be preferable. If the reforms have had a substantial influence on prices, the change in the relationship between agricultural output and inflation, noted above, can be expected to show up in the form of unstable coefficients and a structural break, particularly in the cereal price model.

Another issue of interest is the degree of inflation inertia, measured by the coefficient on lagged inflation. It is usually interpreted as capturing the effects of indexation or inflation expectations. When there is no inertia, the parameters on lagged inflation should be zero. In the other extreme, when the level of inflation is only determined by inertia, the parameters on lagged inflation should sum to unity and all others should be zero. In Ethiopia, indexation has not been common and governmentadministered price setting, which was widespread before, has almost been abolished (IMF, 2008b). Therefore, inertia would probably capture expectations.

\section{The Monetary, External, and Agricultural Sectors}

In this section, we formulate the error correction terms for the monetary and external sectors and calculate the agricultural market output gap. We primarily use cointegration analysis to test for the presence of long-run relationships, but we also use the Hodrick-Prescott filter to obtain estimates of deviations from equilibrium. The use of the Hodrick-Prescott filter is common in the literature on the P-Star model of inflation when analyzing money and foreign exchange markets, and can be viewed as 
an alternative to the cointegration analysis which is especially suitable when data is scarce. $^{7}$

The analysis focuses on the period January 2000-December 2009 but data from January 1999 is used to allow for lags. Although a nationally representative CPI is available from 1997, extending the sample further back in time is challenging: there were significant data revisions of the National Accounts and the CPI methodology in 2000, and the Ethiopia and Eritrea war during 1998-2000 created economic instability. Moreover, data on the euro exchange rate, which we use, is available from January 1999. Appendix A describes the data sources, methods, and definitions of the variables used, while Appendix B provides Augmented Dickey-Fuller unit root tests.

\subsection{The Monetary Sector}

Modeling money demand in Ethiopia is less straightforward than in many other countries because of its small financial sector and government regulation. Interest rates are only partially liberalized: the National Bank of Ethiopia sets the minimum bank deposit rate, while banks are free to set all lending rates and deposit rates beyond the minimum. The minimum interest rate was adjusted only twice between January 1999 and December 2009, and the averaged deposit rates changed only a few more times in spite of the rise in inflation. For instance, the deposit rate was four percent in 2008 while inflation rose to over 60 percent. Moreover, the banking system is characterized by excess liquidity: banks hold about twice as much in reserves in the National Bank of Ethiopia as required (NBE, 2010). Since no interest is paid on excess reserves, banks buy over 80 percent of the treasury bills: the capital account of the balance of payments is closed, so domestic investors are not allowed to use international capital markets. Subsequently, the Treasury bill rate is very low; it has been negative in real terms since mid-2002, and the nominal rate has even been below one percent during recent years. It is thus clear that interest rates are unlikely to be good measures of the costs or returns of holding money.

Another challenge to estimating money demand is the lack of monthly observations on income: only annual data on GDP are available. The annual GDP

\footnotetext{
${ }^{7}$ In the working paper version of this article, Loening et al. (2009) provides an outline of the P-Star model and derivation of the measures. See also Belke and Polliet (2006) on money markets, and Kool and Tatom (1994) and Garcia-Herrero and Pradhan (1998) on foreign exchange markets.
} 
series, measured in millions of birr at 1999/2000 prices, thus had to be interpolated. ${ }^{8}$ Although the interpolation does not create any useful information about short-run fluctuations in income, it produces a monthly series that measures the trend in GDP, which is the relevant variable for long-run money demand analysis.

As a first step, Figure 3 shows the log of velocity, $y-(m-p)$, to highlight the long-run relationship between income, price level and money stock. ${ }^{9}$ Velocity declines continuously from 1999 to 2002 and then rises until 2008; the increase is almost explosive during 2008. Then, as inflation starts to decline in mid-2008, velocity declines as well, first sharply and then slowly. Thus, velocity is not a stationary series; nor is any other linear combination of real money and output.

\section{[Figure 3 here]}

We use the Johansen procedure to test for a long run relationship in the money market, i.e., cointegration. ${ }^{10}$ Apart from interest rates, several variables might influence money demand (Sterken, 2004; Ayalew Birru, 2007). ${ }^{11}$ However, prior tests indicated that only the annual change in the parallel US dollar exchange rate, $\Delta_{12} e u s$, cointegrates with real money and output. Thus, currency substitution seems to be important. Even though there are restrictions on capital flows in Ethiopia, some people hold foreign currency as an alternative to broad money. In fact, US dollars could easily

\footnotetext{
${ }^{8}$ The interpolation was done with the program RATS using the random walk option. To reduce endsample problems when applying the Hodrick-Prescott filter, forecasts for 2010 and 2011 were added to the series. They were based on the IMF's forecasts (IMF, 2010).

${ }^{9}$ Money demand was modeled using both M1 and broad money. The results were very similar so only the results for broad money are reported. Broad money is the intermediate target for the National Bank of Ethiopia (NBE, 2009)

${ }^{10}$ See Juselius (2006) for a detailed description of the Johansen approach.

11 The Treasury bill and deposit rates move too little to explain money demand, so the only standard candidates are inflation, which measures the expected cost of holding money instead of goods, and the rate of change of the value of foreign currency, which measures the expected cost of holding domestic currency instead of foreign currency. A few unconventional variables have been shown to influence money demand in earlier studies. Sterken (2004) finds that food shortages increase money holdings during 1966-1994. Moreover, coffee prices also affect money demand since people store coffee for illegal exports; when real coffee export prices increase, money demand declines. Yet another explanatory variable is international trade. Ayalew Birru (2007) argues that it influences demand for deposits, and finds that real imports enter the demand function for deposits in Ethiopia during 1970 2006. Among these variables, only the change in the value of foreign currency was found to enter longrun money demand during our study period.
} 
be purchased in a semi-official parallel foreign exchange rate market during the study period, except for the period March 2008-June 2008 when the authorities had closed it.

Table 2 shows the test results for $m-p, y$, and $\Delta_{12}$ eus. ${ }^{12}$ The cointegration tests with the other variables are not reported. ${ }^{13}$ There is strong evidence for one cointegrating vector, $(m-p)-0.88 y+1.88 \Delta_{12}$ eus, as the null of one cointegrating vector $($ rank $=0)$ is clearly rejected. The long-run relationship is also evident in Figure 4, which depicts the cointegrating vector. Since the real money stock is endogenous, as indicated by the significant adjustment parameter, $\alpha_{1}$, reported in Table 2, we assume that the cointegrating vector represents long-run money demand. This is a valid interpretation even if the adjustment parameter for $\Delta_{12} e u s$ also is significant, indicating a possible feedback effect. The significance also implies that $\Delta_{12}$ eus is not weakly exogenous, so we use the system estimates of the cointegrating vector when developing single-equation ECMs. Moreover, we note that almost the same cointegrating relationship is obtained using single-equation cointegration tests (see Ericsson and Kamin, 2009, and references therein on this issue).

[Table 2 here]

The coefficient on income is 0.88 . Although consistent with economic theory, it is lower than expected since there is a belief that Ethiopia is going through a process of monetization, which would imply a coefficient greater than unity. Yet, Mathieu (2010) argues that Ethiopia has experienced demonetization during the last decade, which is consistent with our result.

It is surprising that inflation does not enter money demand, but widespread poverty might make the population so dependent on non-durable goods, such as food, that buying durables as a protection against inflation is uncommon. Yet, adding inflation to the cointegrating vector reduces its volatility after 2007, when inflation rose to over 30 percent, so inflation seems to matter when it is sufficiently high. In

\footnotetext{
12 The observations for the four months when the official parallel market was closed, March-June 2008, were interpolated. This does not seem to affect the findings, the long-run results hold also for the period before the closure.

${ }^{13}$ In order not to overburden the reader with tables, we do not report all results. The cointegration tests with the other variables are available on request.
} 
principle, we pick up this effect by adding lags of inflation in the ECMs, but in the section with robustness checks (5.5) we also test if a cointegrating relationship that includes inflation enters any of the models.

As mentioned earlier, we also derive an alternative measure of excess money supply based on the P-Star model. It amounts to calculating the difference between the actual real money stock and the long-run equilibrium levels of output and velocity, $(m-p)-y^{*}+v^{*}$ (see Belke and Polliet, 2006). We use the Hodrick-Prescott filter to estimate $y^{*}$ and $v^{*}{ }^{14}$ The measure obtained is often denoted as the monetary overhang (Gerlach and Svensson, 2003). Figure 5 depicts the monetary overhang. It is similar but not the same as the cointegrating vector in Figure 4.

[Figures 4 and 5 here]

\subsection{The External Sector}

We begin by estimating the long-run relationship for food, equation (3), using the CPI for cereal prices, $p c$, and the World Bank grain commodity price index for world prices, $w f p .^{15}$ The choice of cereal prices instead of food prices is made to get a reasonably good match between domestic and world food prices, although the differences between the CPI index for food and cereals are small as evident from Figure 2. World market prices are converted to local currency using the birr-US dollar exchange rate, $e$.

Figure 6 depicts the cereal price index measured in US dollars, $p c-e$, and $w f p$. The two series follow each other over time, and, as Figure 7 shows, the relative price, $e+w f p-p c$, appears to be a stationary series although the swings around the mean are very large. The birr-US exchange rate hardly changes between mid-1999 and late 2007, so the Johansen approach might not the best choice for cointegration analysis as it is based on maximum likelihood and Gaussian errors. Nonetheless, we use it for consistency with the money demand analysis. When the three variables are entered individually, the trace test indicates that there are two cointegrating vectors (not

\footnotetext{
${ }^{14}$ We set $\lambda$ to 6,400 to obtain a very smooth and slowly changing trend.

${ }^{15}$ The components of the grain commodity index are wheat $(25 \%)$, maize $(41 \%)$, rice $(30 \%)$, barley and sorghum (4\%). The index does not cover teff, a local grain only produced and mainly consumed in Ethiopia and Eritrea, though the teff price closely mirrors movements in major cereal prices. Although it would have been better to have indexes with very similar weights, we preferred to use world grain prices for transparency reasons.
} 
reported). This implies that at least one variable is stationery, which seems unlikely. Moreover, one of the estimated roots is slightly larger than one, i.e., explosive, which seems to be due to $w f p$ though $e$ also seems to be highly non-stationary as evident from the positive and high Dickey-Fuller t-statistic reported in Table B1. We thus reformulated the model, entering $e+w p f$ and $p c$. Table 3 reports tests based on this model. There is one cointegrating vector according to the trace test, and the largest estimated root is now 0.98 (not reported). The long run coefficients have the correct signs and are relatively close to the expected ones, 1 and -0.85 , though the likelihood ratio test for imposing the restrictions $1,-1$ on the $\beta$ vector is significant (Table 3 ). We thus allow for a for a deterministic trend in the cointegrating vector. It has a small coefficient, 0.004 , but makes $e+w f p-p c$ stationary as the likelihood ratio test now is insignificant. The resulting cointegrating vector is thus $e+w f p-p c+0.0046 * t r e n d$. It is visually almost identical to the series plotted in Figure 7. The reason for the significance of the trend is the long swing in $e+w f p-p c$ at the end of the sample, in combination with the short study period.

[Table 3 here]

[Figure 6 and 7 here]

It is important to keep in mind that the relative price series is calculated with indexes (set to unity in 2006:12), and that cointegration does not say anything about the actual price levels. Moreover, the stationarity of the relative price series does not imply that world and domestic prices will converge, only that domestic food prices adjust when relative prices drift far apart.

The log of the non-food relative price is depicted in Figure 7. It is measured with non-food CPI, pnf, the birr-euro exchange rate, $e u$, and the European Union (EU) producer prices, $w p$. The reason for using the euro and EU producer prices is that a large part of Ethiopia's trade is with Europe, about 40 percent of exports and 30 percent of imports (IMF, 2007). The relative price is also easy to calculate, transparent, and works well empirically. We also tested alternative specifications, the birr-US dollar exchange rate, US wholesale prices and the real trade weighted (effective) exchange rate, calculated with weights for the 10 largest trading partners. The real effective exchange rate is in principle the most adequate one, but it works very much 
like the birr-euro exchange rate. Although there are some differences in the series, they nonetheless provide the same information for our purposes.

Figure 8 shows that $e u+w p-p n f$ is not stationary for at least half of the study period, which is also shown by the Johansen cointegration test (not reported). Adding terms of trade does not produce a cointegrating vector. We follow Kool and Tatom (1994) and Garcia-Herrero and Pradhan (1998), because of this, and use the Hodrick-Prescott filter to remove the non-stationary component of the real exchange rate. We thus assume that the trend obtained is the long-run real equilibrium exchange rate, or that it at least captures the long-run level that is relevant for the adjustment of prices in the goods market. Figure 9 shows the variable obtained.

[Figures 8 and 9 here]

\subsection{The Agricultural Sector}

Only annual data is available for agricultural output, so one option is to use the amount of rainfall, as Diouf (2007) does, and another option is to use wholesale prices of agricultural commodities, following Durevall and Ndung'u (2001). We use the annual series for the volume of cereal production, interpolated to monthly observations: the available rainfall data do not work well, and wholesale prices are influenced by many other factors than agricultural supply.

Including the growth rate of agricultural production in the models is not a good idea, since it affects income, which in turn affects demand for food. Therefore, the Hodrick-Prescott filter is used to obtain deviations from the long-run trend in agricultural production. It is assumed that demand grows along with average increases in agricultural production, and that deviations, mainly due to supply shocks, result in price changes. ${ }^{16}$

Figure 10 shows the agricultural output gap and annual inflation for January 1999-December 2009. The counter-cyclical pattern is clearly visible, and there is little doubt that variations in agricultural production affected inflation during the study

\footnotetext{
${ }^{16} \mathrm{We}$ also used value added in agriculture instead of cereal production, but the results are virtually the same. Note that there is some controversy over the data on agricultural output (Rashid, 2010). Hence, we calculated two series, one with the official estimates, and one with estimates for 2008/09 and 2009/10 provided by FAO (2010), but the difference is small (see data appendix for details). The observation for 2010/11, needed for the Hodrick-Prescott filter, is a forecast-based average growth. The series used in the regressions reported is based on data from FAO (2010).
} 
period. It is also evident that other factors influence inflation, particularly since early 2005 when prices continued increasing while the output gap remained positive. Moreover, the rapid rise in inflation in 2008 is not explained by the output gap. ${ }^{17}$

[Figure 10 here]

\section{Determinants of Inflation in Ethiopia}

In this section, we develop single equation ECMs for cereal, food, non-food and overall CPI inflation. The models are estimated with OLS for the period January 2000 (excluding lags) to December 2009. We use general-to-specific modeling, starting with general models that include error correction terms and the agricultural production output gap, and variables in first differences. The reduction of the general model is carried out with Autometrics, a computer-automated general-to-specific modeling approach. Dornik (2008) gives a brief presentation of Autometrics. ${ }^{18}$ Put briefly, the researcher starts by providing a well-specified general model and a significance level. The same significance level is then applied during the whole process of reduction. Autometrics follows a number of reductions paths, checks that the simplified model remains well-specified, and compares resulting models using encompassing tests. The reduction process consists of a multiple-path reduction searches to avoid path dependence. If all reductions, and diagnostic and structural breaks tests, are acceptable then the model becomes a terminal model. If there are several terminal models they are merged into a new general model and the multi-path search iteration is repeated. When this produces more than one terminal model, the Schwarz criterion is used to pick the preferred model, but all the terminal models are reported.

In our view, Autometrics makes the reductions to specific models transparent, thereby facilitating replication, and increasing credibility by reducing the flexibility inherent in general-to-specific modeling (as well as in many other econometric approaches). Automated specification searches are not uncontroversial, however. One

\footnotetext{
${ }^{17}$ The estimated output gap works well in the regressions. However, we cannot rule out that official data overestimate agricultural production (see Rashid 2010 for a critique of official agricultural statistics in Ethiopia).

${ }^{18}$ See Hendry and Krolzig (2005) and Doornik (2009) for detailed descriptions of the methodology of Autometrics, and Ericsson and Kamin (2009), Castle and Hendry (2009) and Ericsson (2010) for applications.
} 
reason is their connection with data mining, even though the purpose of automated specification searches is precisely to avoid (ad hoc) data mining. Another, more substantial critique is that the algorithms used can be overly complex, and there are many ways to evaluate their performance (see Castle et al. (2011) for a discussion). Nonetheless, our findings do not hinge on the use of Autometrics, since the variables of interest are either highly significant or insignificant. ${ }^{19}$

We report results based on models with 12 lags in the general models. The constant and seasonal dummies are forced to remain in all models, i.e., they are fixed. By having a fixed constant we avoid erroneous inclusion of variables when the mean of the dependent variable is different from zero. The seasonal dummies are fixed because we do not have a variable measuring within-year changes in output. The general models contain many parameters, so we use the one percent significance level; the risk of rejecting the null hypothesis and including variables erroneously increases substantially with a five percent significance level in models with many lags. Since misspecification tests of the general models, as well as Figure 1 and 2, indicate the presence of some extreme values, we start by using dummy saturation, a procedure in Autometrics that tests for outliers and unknown structural breaks by including a dummy for each observation, using the 0.1 percent significance level (Santos, 2008; Castle and Hendry, 2009). The standard options in Autometrics are then used to reduce the general models to specific models. We use indexes of the impulse dummies with weights based on their coefficients in the general models to avoid distorting misspecification tests (Hendry and Santos, 2005). We also include variables of interest in the specific models for illustrative purposes, even though they were removed by Autometrics. Moreover, as a robustness check, we report some omitted variables tests and estimates of the models without dummies but with heteroscedastic and autocorrelation consistent (HAC) standard errors.

\subsection{Cereal Prices}

The general model for $p c$ includes a constant and seasonal dummies, the money market and foreign sector error correction terms $(m-p)-0.88 y+1.88 \Delta_{12}$ eus and $e+w f p-p c+0046 t r e n d$, and the agricultural production output gap, ag, lagged one

\footnotetext{
${ }^{19}$ We used a research-based speciation of the models in an earlier version of the article. There are some differences in the short-run part of the models, possibly due to a change in the sample. However, the basic findings are the same.
} 
period. The variables in first differences are broad money, $\Delta m$, birr-US dollar exchange rate $\Delta e$, world food prices $\Delta w f p$, world fertilizer prices $\Delta f e r t$, world energy prices $\Delta e n e r g y$, non-food prices $\Delta p n f$, and lagged cereal prices $\Delta p c$. The contemporaneous values of broad money, birr-US dollar exchange rate and non-food prices are not included to avoid simultaneity bias, though this does not affect the final results.

The dummy saturation procedure found outliers in January 2001 and during the period of extreme volatility, May 2008-December 2008. The January 2001 outlier is due to an unexplained jump in food CPI, which was created by the revision of CPI in 2006; there is no jump in the old series. The other outliers are due to the almost explosive rise in cereal prices before harvest. We interpret them as a consequence of forward-looking expectations, or speculative storage, as outlined in the microeconometric work of Osborn (2004) and Tadesse and Guttormsen (2011). When the dummy variables are added to the general model, the misspecification tests for serial autocorrelation, autoregressive heteroscedasticity, heteroscedasticity, normality and non-linearity are all insignificant. ${ }^{20}$

Autometrics produces two very similar terminal models and the final selection is based on the Schwartz criteria; the choice of model does not affect the basic findings reported below. Table 4 reports the specific model as Model 1, which also contains some other variables of interest, while Table 5 reports $\mathrm{R}^{2}$, residual standard error, and misspecification tests.

The external sector error correction term is highly significant ( $\mathrm{t}$-value $=8.0$ ), while the money market error correction term, included for information purposes, is insignificant and has the wrong sign. This means that world food prices and the exchange rate seem to determine the evolution of domestic cereal prices: one percent increase in world prices raises the domestic price level by one percent in the long run, given the exchange rate. When there is disequilibrium in the external sector for food, about 11 percent of the disequilibrium is removed every month by changes in domestic prices, again assuming the exchange rate is constant, so it takes approximately six months for half of the disequilibrium to disappear.

\footnotetext{
${ }^{20}$ Due to space limitations, the general models are not reported. They can be obtained from the authors on request.
} 
The agricultural output gap is also important. Its coefficient is -0.24 (t-value $=$ -7.8). It explains most of the swings in cereal prices away from long-run equilibrium. The impact is quite large: a hypothetical shift from no output gap to a serious drought, such as in 2003 , would raise cereal price inflation by up to four percentage points per month, calculated as the coefficient on $a g$ times the minimum value of $a g$ during the drought, -0.20 . A rough calculation indicates that such a drought would increase annual cereal price inflation from zero to up to approximately 30 percent within a year if all the other explanatory variables have zero impact. Since the impact of the drought is temporary, inflation would then decline.

Apart from the output gap, the only significant variables entering the short-run part of the model are cereal price inflation lagged five months, the rate of change of food imports lagged twelve months, and world energy price inflation lagged eight months. Lagged cereal price inflation has a negative coefficient, while the other two have small positive coefficients. The impact of world energy price inflation is not strong; recursive estimation shows that it becomes significant first after including a large part of the sample. This is probably because the government controlled fuel prices during a large part of the study period, until October 2008, making the link highly non-linear. We are also likely to be capturing the cost of energy indirectly through its impact on world market food prices.

Lagged money growth is included for comparative purposes, since it is significant in the model of non-food inflation. However, money does not seem to have a direct effect on cereal prices.

World fertilizer prices do not have a significant effect either. This is probably because of the small use of fertilizers by the majority of rural households. Alternatively, an index specified for Ethiopia might provide more information, but unfortunately the monthly data on the value and volume of fertilizer imports are not detailed enough to allow sensible calculations of unit values.

One issue raised in the discussion of Ethiopia's inflation is that structural reforms might be a major cause of the surge in food prices, at least between 2004 and 2008 (Ahmed, 2007); the main factors would be reduced distress selling, speculative storage, and switch from food to cash aid. Indirect evidence for an impact of reforms on the formation of cereal prices can be obtained with Chow tests, a structural change 
should induce a break in the model. Figure 11 accordingly reports one-step, break point and forecast Chow tests for the period January 2001-December 2009. The Chow tests are far from significant at the one percent level, indicated by the straight line at 1.0. Thus, although structural changes in the grain market would need to be assessed more directly with microeconomic surveys, we fail to find evidence of a structural break in our model.

[Figure 11 here]

Since all diagnostic tests are insignificant (see Table 5), as well as the Chow tests in Figure 11, the model is reasonably well specified and empirically stable, albeit with some dummy variables. It explains 85 percent of the variation in cereal inflation as measured by the $\mathrm{R}^{2}$, which is quite good given that we use noisy monthly data.

\subsection{Food Prices}

The general model for food inflation is specified in the same way as the one for cereal price inflation. Autometrics only produces one terminal model (Model 2, Table 4). The results are also similar to the cereal price inflation model. The most notable difference is that the coefficients for the external-sector error correction term and the output gap are smaller in the food price model. This is because cereal prices fluctuate more than other prices in the food price index (see Figure 2). The adjustment process towards the long-run equilibrium is 6.5 percent instead of 11 percent per month, so it takes about ten months before 50 percent of shock has been removed. Moreover, the coefficient of the agricultural output gap is -0.11 , instead of -0.23 .

Another difference is that energy price inflation enters lagged four months instead of eight months, and that lagged food inflation does not enter the model. We have added the eighth lag of energy price inflation to show that it is a borderline case $(\mathrm{t}-\mathrm{value}=1.98)$.

The model is well specified, as indicated by the diagnostic tests in Table 5, and it has stable coefficients, as illustrated by recursive estimates of the coefficients for $[e+w f p-p c+0.0046 t r e n d]_{t-1}, a g_{t-1}$ and the constant (Figure 12), which also support the previous finding of no detectable effect of structural change. Chow test statistics 
are similar to the ones for Model 1; none is significant at the one percent level (Figure 13).

[Figures 12 and 13 here]

We thus conclude that cereal and food prices seem to be determined by the exchange rate and foreign prices in the long run. The domestic agricultural market also plays an important role by generating supply shocks, while excess money supply or money growth does not seem to affect either price directly.

To illustrate the relative importance of changes in world food prices and the birr-US dollar exchange rate for the rise in food prices, Figure 14 plots the actual price, $p f$, together with two 'simulated' food price series over January 2004-December 2009. The illustration is based on the assumption that $p f=e+w f p$ in the long run, ignoring the (weak) trend, and that $p f$ and $e+w f p$ are the same in 2004:1, i.e. zero for simplicity. If the world food price would have remained constant (at zero), the domestic food price would have followed the exchange rate, and if the exchange rate would have remained constant (at zero), the domestic food price would have followed the world food price index. These calculations do not capture potential indirect effects of world food prices on food prices via their impact on the exchange rate. Nonetheless, Figure 14 shows that world food prices contributed greatly to the rise in food prices, particularly during 2006-2008. Exchange rate devaluations played a minor role during this period, as the birr remained relatively stable, but they probably prevented food prices from falling in line with the decline in world food prices after mid-2008.

[Figure 14 here]

\subsection{Non-food Prices}

The specification of the general model for non-food inflation includes the money market term $(m-p)-0.88 y+1.88 \Delta_{12} e u s$, and the external sector error correction term $e u+w p-p n f-\tau_{1}$, where $\tau_{1}$ is obtained with the Hodrick-Prescott filter. The other explanatory variables are the agricultural output gap $a g_{t-1}$, first differences of broad money $\Delta m$, the birr-euro exchange rate $\Delta e u$, world goods prices $\Delta w p$, world energy prices $\Delta e n e r g y$, food prices $\Delta p f$, and non-food prices $\Delta p n f$. 
Only lags of broad money, exchange rate, food and non-food prices enter the model. Since no misspecification test of the general model are significant (not reported), no dummies are included.

Autometrics produces two terminal models, which differ in terms of lags of the dependent variable and lagged money growth. The selected model contains lagged money growth (Model 3 in Table 4 and 5). It is well specified, but modeling non-food inflation is a challenge, as indicated by the $\mathrm{R}^{2}$; it is only 0.34 , compared to 0.82 for food prices. Moreover, the t-values are clearly lower than in the two previous models.

The error correction term for the external non-food sector is significant, and the monthly adjustment back to equilibrium after a shock is nine percent. The money market error correction is, as before, not significant, but money growth lagged nine months has a t-value of 3.11 . Its coefficient is 0.23 , so money growth seems to affect non-food inflation in the short run. There is also some inertia, since lagged non-food price inflation enters the model; the coefficient is 0.27 .

\subsection{CPI Inflation}

We combine variables in the models for food and non-food price inflation when formulating the general model for CPI inflation, except that lagged food and non-food inflation are not included. This means we have two error correction terms for the external sector, $e u+w p-p n f-\tau_{1}$ and $e+w f p-p c+0.0046$ trend. Dummy saturation indicated an additional outlier, in May 2006 (see footnote in Table 4). The resulting parsimonious model, Model 4, is well specified as shown in Table 5. There were two terminal models; the one chosen excluded contemporaneous world non-food price inflation.

The only error correction term that remained in the specific model is $e+w f p-p c+0.0046$ trend $(\mathrm{t}$-value $=7.7)$; excess money supply is not significant and has the wrong sign. Moreover, the agricultural output gap is highly significant (t-value $=-6.5)$. This indicates that inflation in Ethiopia during the study period was primarily food inflation, and that long-run price increases were determined in the foreign food sector. The adjustment after disequilibrium in the international food sector is four percent per month, which is slow.

The coefficient on the output gap is -0.6 , which makes sense: it is about onequarter of the coefficient in the model for cereal prices, and the weight of cereal prices in CPI is 22.54 percent. Hence, using the same hypothetical example as above for 
cereal prices, a shift from no output gap to a serious drought would raise monthly CPI inflation from zero to over one percentage point, and by about eight percent per year.

We have added $e u+w p-p n f-\tau_{1}$ and $\Delta m_{t-9}$ to the specific model. They are significant at the five percent level only, as they mainly affect non-food price inflation. Nonetheless, they indicate that better models are obtained when analyzing food and non-food prices separately.

There is also some inflation inertia as in the non-food inflation model, but it is small, 0.15. Moreover, the first difference of the birr-euro exchange rate enters lagged eleven months and energy price inflation enters lagged three months, but both variables have small coefficients.

\subsection{Robustness Checks}

In this section, we carry out omitted variables tests, re-estimate the models without dummy variables, and produce forecasts, to check the robustness of the results.

The omitted variables test statistics are reported in Table 6. The alternative measure for the money market, the monetary overhang of the P-Star approach, is clearly insignificant in all models except food inflation, where its p-value is six percent. Moreover, it was never retained when included in general-to-specific modeling with Autometrics. Next the long-run money demand relationship expanded with annual inflation was tested, but it is not significant in any model. We also tested the rate of change of reserve money (base money), which is the operational target of the National Bank of Ethiopia (NBE, 2009). It was entered with twelve lags. None of the tests is even close to significant at the ten percent level.

Table 7 reports estimates of Model 1,2 and 4 without dummy variables but with HAC standard errors that correct for heteroscedasticity and autocorrelation. The regressions provide the same message as the ones with dummy variables: the coefficients are similar, and the error correction term for the external food sector and the agricultural output gap are highly significant in all three models, while the error correction term for the monetary sector is insignificant. The only substantial difference is that the rate of change of lagged exchange rate in the CPI model is not significant any longer.

[Table 6 and 7 here] 
As a final robustness check, we forecast inflation from January 2010 to December 2012. This exercise allows us to compare forecasted and actual inflation figures, highlighting the model's performance until December 2012. We focus on the cereal price inflation, since cereal prices are the key to explaining overall food and CPI inflation. Figure 15 shows that CPI inflation is practically synonymous with food inflation from 2010 to 2012, which in turn is closely related to cereal price inflation. And, as Figure 16 shows, cereal price inflation in Ethiopia follows world grain price inflation over the period. Forecasting food or CPI inflation gives practically the same results as forecasting cereal price inflation.

[Figures 15 and 16 here]

Only lagged explanatory variables enter the model, so we can produce monthly (one-step) forecasts using their actual values. An alternative is to carry out dynamic forecasts, where the predicted value for one month is used as input when predicting inflation the following months, but the results are similar to the one-step forecasts, as we would be using actual values of all variables except cereal prices.

To implement the forecasts, we use Model 1 in Table 5. The deterministic trend in the error correction term is set to zero for the forecasting period. To facilitate the interpretation of the results, we report forecasts of annual inflation. Figure 17 shows the predicted and actual values and $95 \%$ error bars.

Overall, the model predicts annual changes in cereal prices well, and a test of numerical parameter constancy over the forecast period is insignificant: $\mathrm{F}(36,102)=$ 1.22 [0.22] (Doornik and Hendry, 2009). There are small but statistically significant forecast errors in early 2011 and 2012 as a result of unusually high price increases in March each year; the volatility in early 2011 is probably related to a combination of rapid increase in world grain prices during 2010 and price controls on a number of food items from January to June 2011 . Nonetheless, the model clearly picks up the swings in cereal price inflation during January 2010-December 2012.

[Figures 17 here] 


\section{Discussion}

In this section we discuss two of our key findings: How do we explain that global food prices matter in Ethiopia? And how do we explain the limited role of monetary policy?

The prevailing view in Ethiopia is that international trade in food is too limited to allow world market prices to be transmitted to domestic prices. Moreover, there are large deviations from the law of one price of, for example, maize and wheat, so traders do not seem to exploit business opportunities (Ahmed, 2007; Dercon, 2009; Rashid, 2010). In contrast to this view, we find that the long-run evolution of food prices in Ethiopia is determined in the external sector.

To evaluate transmission mechanisms from world to domestic food prices, we highlight a few issues. First, the finding of a strong link between domestic food and world food prices is consistent with the observed large fluctuations of prices above or below import or export parity bands. Domestic food supply shocks have a strong effect on food inflation in the short to medium run, causing large deviations from long-run equilibrium. This occurs because there are substantial market distortions. Restricted access to foreign exchange, limited credit availability, and general uncertainty in the private sector about government interventions, seem to inhibit traders from taking advantage of significant business opportunities that arise when there are large differences in domestic and foreign prices.

Second, the food price error correction term measures excess supply and demand in the market for cereals, where not only the private sector, but also the government and donors are important actors. Since both the government and donors have responded to variations in harvests, at least since the mid-1990s, by increasing or decreasing exports and imports of grain and food aid, they probably have limited the impact of local supply shocks on food prices and prevented them from moving far away from world market prices. Thus, private sector arbitrage as typically understood might not be the only mechanism behind the price transmission.

Third, the authorities liberalized the domestic market for cereals in the beginning of the 1990s, so domestic prices are market determined. An important feature in this regard is the centralized wholesale grain market structure and improved information flows due to public investments in infrastructure. For example, Getnet, Verbeke and Viaene (2005) find that the wholesale market exhibits large concentration power and transmits price signals into the local producer markets. Thus, the 
wholesalers are likely to be large enough to be lined up with world markets, transmitting major changes in world market prices to domestic markets. Furthermore, their results show - taking the example of white teff - that wholesale prices in Addis Ababa seem to determine both short- and long-run prices in local supply markets. To this should be added that brokers in Addis Ababa handle a very large fraction of the grain trade in Ethiopia, making the city a de facto clearing house for the country. These brokers are typically well-informed and have information about both domestic and international food prices. And as shown by Stephens et al. (2012) for Zimbabwe, there can be price transmission even without trade.

Finally, although Ethiopia's international trade in food items is very tiny relative to total agricultural production, it is not that small when compared to the total volume of marketed products. In quantity terms, the share of marketed crops from total agricultural production is about one-third, and the share of agricultural exports from total marketed agricultural production, which includes coffee, may reach up to 30 percent. To this should be added that there is some unofficial trade with neighboring countries, although little is known about its size. In other words, prices may matter at the margin, and a few internationally marketed products may transmit price signals into the subsistence sectors. $^{21}$

We do find a short-run impact from lagged money growth on non-food price inflation. However, excess money supply does not seem to have a direct impact on inflation in the long run. The lack of significance of excess money could be due to the use of a small sample (11 years of monthly data). However, as many other variables are highly significant, insignificance is probably an indication of a relatively weak impact. Another possibility is that it affects inflation indirectly, via the nominal exchange rate. However, excess money does not become significant when our models are re-estimated without the exchange rate error correction terms, nor does it enter significantly in models of the birr-US dollar exchange rate (results not reported, but available from the authors).

If excess money supply were an important cause of exchange rate changes, expansionary monetary policy would indeed play an active role in generating inflation. Since there are restrictions on capital flows, the most likely channel would be via

\footnotetext{
${ }^{21}$ For example, Ulimwengu, Workneh and Paulos (2009) find significant short-term price transmission between the world maize prices and prices recorded in the Ethiopian regional markets bordering Sudan.
} 
current account/foreign reserves, which might force NBE to devalue the birr. However, during our study period, external shocks, such as changes in commodity prices, particularly coffee and oil prices, and fluctuations in foreign aid were probably much more important than excess money supply. Nonetheless, our main finding that foreign food prices (combined with domestic food supply shocks) are the primary drivers of inflation in Ethiopia during the study period would still hold even with a strong effect of money on the exchange rate. This is illustrated by Figure 14 that decomposes the effects of world food prices and the exchange rate on domestic food prices; world food prices are clearly more important than the exchange rate, even though we do not control for indirect effects of prices on the exchange rate.

In our view, the main reason for not finding that excess money causes long-run inflation directly is that monetary policy may have been ineffective due to excess liquidity in the banking system. Ethiopia has very large excess reserve ratios even by Sub-Saharan African standards; according to Saxegaard (2006), only Equatorial Guinea had a higher ratio in 2004. In an environment with large holdings of excess reserves, the monetary transmission mechanism is likely to be weakened or even interrupted completely (O'Connell, 2005). This is because banks can easily adjust excess reserve ratios when money demand changes, making the link between base money, which the central bank controls, and the money stock unstable. Moreover, banks can themselves generate money supply shocks. In Ethiopia, the link between base money and broad money was very weak during the study period, as evident from a visual inspection of their trajectories during the last decade.

Another reason is that money demand could be unstable, as a large part of the Ethiopian economy is not monetized, particularly the rural areas, and there is a great deal of barter trade. Movements of trade in and out of the monetized sector could affect the coefficients in the money demand function. Moreover, most Ethiopians have very limited options to shift from money to other assets. This is probably the reason why the parallel US dollar exchange rate is the only opportunity cost variable that enters our long-run money demand equation.

\section{Conclusion}

We analyze the determinants of inflation in Ethiopia by estimating error correction models for cereal, food and non-food consumer prices and CPI using monthly data 
from January 1999 to December 2009. The resulting models are highly parsimonious and robust to standard misspecification tests.

Our results show that inflation in Ethiopia is heavily associated with the dominant role of agriculture and food in the economy. In fact, Ethiopia's inflation was practically synonymous with food price inflation during the study period. In the long run, food prices seem to be determined in the external sector, i.e., the exchange rate and international food prices explain the evolution of Ethiopia's food prices. In the short run, domestic agricultural supply shocks, as well as inter-seasonal fluctuations, which probably are induced by expectations about future harvests, cause large deviations from the long-run relationship between domestic and foreign food prices. However, the mechanisms that link world food prices to domestic food prices are not well understood since there is limited scope for arbitrage. Thus, there is a need for further research, focusing on individual food prices.

Non-food prices are also determined by international prices in the long run. In contrast to food prices, money supply has a direct impact, though only in the short run through changes in money growth.

Persistent domestic price increases eventually affect the exchange rate. Nonetheless, it is the rise in world food market prices that explains the atypical occurrence of both food price inflation and high growth rates in agricultural production during 2004-2008, not devaluations.

Although not analyzed in the article, the reason for the passive role of money is probably the structure of the financial system and the existence of large excess reserves, which thwart the National Bank of Ethiopia's control of money supply. In other words, the money stock does not seem to have served as a nominal anchor for the domestic price level. An alternative interpretation is that expansionary monetary policy caused devaluations, which in turn affected inflation. Though unlikely, this is a topic that merits further study. However, the finding of monetary transmission through exchange rate depreciation would not undermine our finding about the importance of international food prices, as evident from Figure 14.

We fail to find evidence that structural change in the agricultural sector has had a substantial impact on food price inflation. This finding is based on the stability of the empirical models and their coefficients. The test is indirect, but in our view, the finding is plausible because structural change is unlikely to generate high inflation over several years. 
World-energy price inflation only seems to have a small short-run direct effect on domestic inflation. This is probably because the authorities subsidized fuel until October 2008, keeping domestic prices low. It could also be because we indirectly capture oil price inflation through its effect on world food and non-food prices.

Two policy conclusions emerge from the analysis. To make monetary policy more effective, the functioning of the financial sector should be improved. With control over money supply, world market price hikes and domestic supply shocks can be managed better, reducing second-round feedback effects and rises in inflation. In addition, measures to boost and stabilize domestic agricultural supply and productivity, particular for major food staples, are of cardinal importance because negative supply shocks raise food prices sharply.

Our analysis should be viewed as what Hendry (1995) calls a "progressive strategy" where models and knowledge can improve over time. Nevertheless, we believe that our results highlight the need to consider a country's specific institutional and macroeconomic context when analyzing world food price transmission. And for developing economies with a large food share in consumer prices, world food prices and domestic agricultural production factors should be considered when analyzing determinants of inflation. Omitting these factors can lead to biased results and misguided economic policy decisions.

\section{Acknowledgements}

We would like to thank the anonymous referees, the co-editor Chris Udry, and Philip Abbott, Chris Adam, Hashim Ahmed, Arne Bigsten, Robert Corker, Shantayanan Devarajan, Astou Diouf, Paul Dorosh, Karen Mcconnell-Brooks, Jiro Honda, Deepak Mishra, Paul Moreno-Lopez, Rashid Shahidur, Eleni Gabre-Madhin, Francis Rowe, Steven O'Connell, Cristina Savescu, Emily Sinnott, and Zaijin Zhan, as well as participants of the World Bank's 2009 Economists' Forum, for useful comments and discussions. This article initiated while Josef Loening worked at the World Bank. The views expressed in this article are the authors and do not necessarily represent the views of the institutions we are affiliated with. 


\section{References}

Admassie, A. 2013. "The political economy of food prices: The case of Ethiopia." WIDER Working Paper 2013/001. United Nations University.

Ahmed, H.A., 2007. Structural analysis of price drivers in Ethiopia. Mimeo, Addis Ababa: Ethiopian Development Research Institute.

Alem, Y., Söderbom, M., 2012. Household-level consumption in urban Ethiopia: The effects of a large food price shock. World Development 40(1), 146-162.

Al-Mashat, R., Billmeier, A., 2008. The monetary transmission mechanism in Egypt. Review of Middle East Economics and Finance. 4(3), 32-82.

Ayalew Birru, Y., 2007. Explaining the current sources of inflation in Ethiopia: A macroeconometric approach. Mimeo, Addis Ababa: National Bank of Ethiopia.

Baffes, J., Haniotis, T., 2010. Placing the 2006/08 commodity price boom into perspective. Policy Research Working Paper 5371, The World Bank.

Baltzer, K. 2013. "International to domestic price transmission in fourteen developing countries during the 2007-08 food crisis.” WIDER Working Paper 2013/031. United Nations University.

Barnichon, R., Peiris, S.J.. 2008. Sources of inflation in sub-Saharan Africa. Journal of African Economies 17(5), 729-746.

Belke, A., Polliet, T., 2006. Money and Swedish inflation reconsidered. Journal of Policy Modeling 28(8), 931-942.

Bigsten, A., Shimeles, A., 2008. Poverty transition and persistence in Ethiopia: 1994-2004. World Development 36(9), 1559-1584.

Blavy, R., 2004. Inflation and monetary pass-through in Guinea. IMF Working Paper WP/04/223.

Castle, J.L., Hendry, D.F., 2009. The Long-run determinants of UK wages, 1860-2004. Journal of Macroeconomics 31(1), 5-28.

Castle, J., Qin, X., Reed, R., 2011. Using model selection algorithms to obtain reliable coefficient estimates Journal of Economic Surveys. 27(2), 269-296.

Dercon, S., 2009. Rural poverty: Old challenges in new contexts. The World Bank Research Observer 24(1), 1-28.

Diouf, M.A., 2007. Modeling inflation for Mali. IMF Working Paper WP/07/295.

Doornik, J., 2008. Encompassing and automatic model selection. Oxford Bulletin of Economics and Statistics, 70(s1), 915-925.

Doornik, J. (2009) Autometrics. Chap. 4 in Castle, J., Shephard, N. (Eds.) The Methodology and Practice of Econometrics - A Festschrift in Honour of David F. Hendry. Oxford: Oxford University Press.

Doornik, J. A., Hendry, D.F., 2009. Empirical Econometric Modelling - PcGive

13, vol. 2. London: Timberlake Consultants Ltd.

Dornbusch, R., 1980. Open Macroeconomics. New York: Basic Books.

Dridi, J. Zieschang, K., 2002. Compiling and using export and import price indices. IMF Working Paper WP/02/230.

Durevall, D., 1998. The dynamics of chronic inflation in Brazil, 1968-1985. Journal of Business and Economics Statistics, 16(4), 423-432.

Durevall, D., Ndung'u, N., 2001. A dynamic model of inflation of Kenya, 1974-96. Journal of African Economies 10(1), 92-125.

Ericsson, N.R., 2010. Empirical model selection: Friedman and Schwartz revisited. Mimeo, available at http://www.gwu.edu/ forcpgm/NeilEricsson-FSGets-March2010.pdf

Ericsson, N.R., Kamin, S.B., 2009. Constructive data mining: Modeling Argentine broad money demand. Chap. 17 Castle, J., Shephard, N. (Eds.) The Methodology and Practice of Econometrics - A Festschrift in Honour of David F. Hendry. Oxford: Oxford University Press.

FAO. 2010. Crop prospects and food situation. No. 2, May, Rome: Food and Agricultural Organization of the United Nations.

Garcia-Herrero, A., Pradhan, M.V., 1998. The domestic and foreign price gaps in the P-STAR model: Evidence from Spain. IMF Working Paper WP/98/64.

Gerlach, S., Svensson, L.E.,. 2003. Money and inflation in the euro area: A case for monetary indicators? Journal of Monetary Economics 50(8), 1649-1672.

Getnet, K., Verbeke, W., Viaene, J., 2005. Modeling spatial transmission of the grain markets of Ethiopia with an application of ARDL approach to white teff. Agricultural Economics 33(3), 491-502.

Government of Ethiopia. 2012. Ethiopia's progress towards eradicating poverty: An interim report on poverty analysis study (2010/11). Development Planning and Research Directorate, Ministry of Finance and Economic Development, Addis Ababa. 
Hanson, J. A., 1985. Inflation and imported input prices in some inflationary Latin American Economies. Journal of Development Economics 18, (2-3) 395-410.

Hendry, D. F., 1995. Dynamic Econometrics. Oxford: Oxford University Press.

Hendry, D. F., Krolzig, H-M., 2005. The properties of Automatic Gets modelling. Economic Journal 115(502), C32-C61.

Hendry, D.F., Santos, C., 2005. Regression models with data-based indicator variables.

Oxford Bulletin of Economics and Statistics, 67(5), 571-595.

Hendry, D. F., Nielsen, B., 2007. Econometric modeling: a likelihood approach. Princeton: Princeton University Press.

IMF 2007. Statistical Appendix, Prepared by the Ethiopian Authorities (In Conjunction with the IMF Staff Report for the 2007 Article IV Consultation) Washington DC: International Monetary Fund

IMF. 2008a. Federal Democratic Republic of Ethiopia: 2008 Article IV Consultation Staff Report. IMF Country Report 08/264. Washington DC: International Monetary Fund.

IMF. 2008b. Food and Fuel Prices: Recent Developments, Macroeconomics Impact, and Policy Responses. Fiscal Affairs, Policy Development and Review, and Research Departments, June 30, Washington DC: International Monetary Fund.

IMF. 2008c. Federal Democratic Republic of Ethiopia: Selected Issues. IMF Country Report 08/259. Washington DC: International Monetary Fund.

IMF. 2010 Ethiopia: 2010 Article IV Consultation and First Review of the Arrangement under the Exogenous Shocks Facility-Staff Report; Staff Supplements; and Press Release on the Executive Board Discussion. Country Report No. 10/175, Washington DC: International Monetary Fund.

Jonsson, G., 2001. Inflation, money demand, and purchasing power parity in South Africa. IMF Staff Papers 48(2), 243-265.

Juselius, K., 1992. Domestic and foreign effects on prices in an open economy: The case of Denmark. Journal of Policy Modeling 14(4), 401-428.

Juselius, K., 2006. The Cointegrated VAR Model: Methodology and Applications. Oxford: Oxford University Press.

Kamin, S., 1996. Real exchange rates and inflation in exchange rate-based stabilizations: An empirical examination. International Finance Discussion Papers 554, Board of Governors of the Federal Reserve System.

Kinda, T., 2011. Modeling inflation in Chad. IMF Working paper WP/11/57.

Klein, N., Kyei, A., 2009. Understanding inflation Inertia in Angola. IMF Working Paper WP/09/98.

Kool, C.J., Tatom, J.A., 1994. The P-STAR model in five small economies. Federal Reserve Bank of St. Louis Review 76(2), 11-29.

Loening, J., Durevall, D., Birru, Y.A., 2009. Inflation dynamics and food prices in an agricultural economy: The case of Ethiopia. World Bank Policy Research Working Paper Series, No. 4969.

Loening, J., Masato T., 2011. Decomposing terms of trade fluctuations in Ethiopia. Applied Economic Letters 18(13), 1219-1224

Mathieu, P., 2010. For sustained growth, Ethiopia needs to promote re-monetization. IMF Survey Magazine: Countries and Regions, June 22.

Minot, N.. 2010. Transmission of world food price changes to African markets and its effect on household welfare. Prepared for the Comesa policy seminar Food price variability: Causes, consequences, and policy options on 25-26 January 2010 in Maputo, Mozambique under the Comesa-MSU-IFPRI African Agricultural Markets Project (AAMP).

Moriyama, K.. 2008. Investigating inflation dynamics in Sudan. IMF Working Paper WP/08/189.

NBE. 2009. Monetary policy framework of Ethiopia, Addis Ababa: National Bank of Ethiopia.

NBE. 2010. Quarterly Bulletin, 24(4) Addis Ababa: National Bank of Ethiopia.

Nell, K.S.. 2004. The structuralist theory of imported inflation: an application to South Africa. Applied Economics 36(13), 1431-1444.

O'Connell. S., 2005. Note on excess liquidity. Mimeographed, Washington D.C.: International Monetary Fund.

Olubusoye, O., Oyaromade, R., 2008. Modelling the inflation process in Nigeria. AERC Research Paper 182, African Economic Research Consortium, Nairobi.

Osborne, T., 2004. Market news in commodity price theory: Application to the Ethiopian grain market. The Review of Economic Studies, 71(1), 133-164.

Rashid, S., 2010. Staple food prices in Ethiopia. Prepared for the Comesa policy seminar Food price variability: Causes, consequences, and policy options on 25-26 January 2010 in Maputo, 
Mozambique under the Comesa-MSU-IFPRI African Agricultural Markets Project (AAMP). Santos, C., 2008. Impulse saturation break tests. Economic Letters 98(2), 136-143.

Saxegaard, M., 2006. Excess liquidity and the effectiveness of monetary policy: Evidence from subSaharan Africa. IMF Working Paper WP/06/115.

Stephens, E., Mabaya, E., von Cramon-Taubadel, S., Barrett, C.B., 2012. Spatial price adjustment with and without trade. Oxford Bulletin of Economics and Statistics, 74(3), 453-469.

Sterken, E., 2004. Demand for money and shortages in Ethiopia. Applied Economics Letters 11(12), 759-769.

Tadesse, G., Guttormsen A. 2011.The behavior of commodity prices in Ethiopia. Agricultural Economics 42(1), 87-97.

Ulimwengu, J.M., Workneh, S., Paulos, Z., 2009. Impact of soaring food price in Ethiopia: Does location matter? IFPRI Discussion Paper 846.

Wodon, Q., Zaman, H., 2010. Higher food prices in Sub-Saharan Africa: Poverty impact and policy responses. World Bank Research Observer 25(1): 157-176.

World Bank, 2012. GEM Commodities, available at http://data.worldbank.org/datacatalog/commodity-price-data 


\section{Appendix A: Data Sources and Definitions}

Agricultural output gap: Annual agricultural production data is from the Central Statistical Agency of Ethiopia. The monthly agricultural output gap was estimated by interpolating annual crop production, cereals in metric ton, to monthly observation with the procedure "Distribute" from the RATS econometrics software package. The underlying process was assumed to follow a random walk process. The trend in agricultural production was estimated with the Hodrick-Prescott filter assuming $\lambda=$ 6,400 .

There is some uncertainty regarding the data (Rashid, 2010), so we used both the official data for the most recent years and FAO (2010) estimates. Official data shows that growth was 6 percent in 2008/09, and forecasted to be 6.2 percent in 2009/10. The value for 2010/11 is assumed to be in line with the average growth rate since 2003/04, i.e., 7.0 percent, since this is the best guess we can make. FAO $(2009,2010)$ estimates growth to 2 percent in 2008/09 and 3 percent in 2009/10. The level of output is assumed on track in 20010/11, implying 10 percent growth. In the paper, we report the results with the latter calculation of cereal production, but the difference between the two series is too small compared to the volatility of inflation to matter empirically.

Consumer prices indexes: Central Statistical Agency of Ethiopia. The base is December 2006. Observations for July and August 2000 for the Food CPI and overall CPI are interpolated, in consultation with the Central Statistical Agency.

GDP: National Bank of Ethiopia. GDP at 1999/2000 constant prices in millions of birr. The growth rates for 2009/10 and 2010/11 were based on IMF's forecasts, 7 and 7.7 percent (IMF, 2010). Monthly GDP was estimated by interpolating annual GDP with RATS. The underlying process was assumed to follow random walk process. The trend in GDP was estimated with the Hodrick-Prescott filter assuming $\lambda=6,400$.

Money supply: Reserve money and broad money are from the National Bank of Ethiopia.

Nominal exchange rates: The US dollar - birr and euro - birr exchange rates were obtained from International Financial Statistics of the IMF, monthly average rates. The parallel exchange rate is from the National Bank of Ethiopia. A few observations missing because of the temporary closure of the parallel foreign exchange market, 
March-June 2008, were interpolated.

Real effective exchange rate: Own calculations with weights for the 10 largest trading partners, based on data from the National Bank of Ethiopia and IFS.

Terms of trade: Following Loening and Masato (2011) we calculated the simple terms of trade index. To construct the export and import price indexes we followed Dridi and Zieschang (2002). We used data from the Ethiopia's customs authorities on trade values and volumes, domestic prices from the National Statistical Agency, and the IMF World Market Price Index. Trade values were converted into birr using the official birr-US dollar exchange rate.

World commodity prices: Various indexes from the Development Prospects Group of the World Bank as of July 2010. The grain price index is a weighted average of rice, maize, wheat, barley and sorghum. The energy price index is a weighted average of natural gas and crude oil. The fertilizer index is a weighted average of phosphate rock, phosphate, potassium and nitrogenous.

World non-food producer prices: Producer price indexes are from the euro area only, obtained from Eurostat, the dataset name is Short Term Statistics. The US producer prices are the wholesale price index, obtained from International Financial Statistics of the IMF. 
Table A1. Variable definitions

\begin{tabular}{|l|l|}
\hline \multicolumn{2}{|l|}{ Variables (in logs) } \\
\hline$p$ & CPI \\
\hline$p n f$ & Non-food CPI \\
\hline$p f$ & Food CPI \\
\hline$p c$ & Cereal CPI \\
\hline$e$ & Birr-US dollar exchange rate \\
\hline$e u$ & Birr-Euro exchange rate \\
\hline$\Delta_{12} e u s$ & Annual change in birr-US dollar exchange rate \\
\hline$w f p$ & International grain price index \\
\hline$w p$ & International producer prices \\
\hline$y$ & GDP \\
\hline$m$ & Money stock, M2 \\
\hline$m-p$ & Real money stock, M2 \\
\hline$a g$ & Agricultural output gap \\
\hline$e u-w p-p n f$ & Relative non-food prices/real exchange rate, non-food \\
\hline$e-w f p-p c$ & Relative cereal price/real exchange rate, food \\
\hline$\Delta f e r t$ & Growth rate in international fertilizer price index \\
\hline$\Delta e n e r g y$ & Growth rate in international energy price index \\
\hline
\end{tabular}




\section{Appendix B: Unit Root Tests}

Table B1. Augmented Dickey-Fuller tests, January 2000-December 2009

\begin{tabular}{lcllll}
\hline Variables & t-ADF & Lags & Variables & t-ADF & Lags \\
\hline$p$ & -1.49 & 1 & $\Delta p$ & $-5.26^{* *}$ & 0 \\
$p n f$ & 1.20 & 0 & $\Delta p n f$ & $-4.65^{* *}$ & 1 \\
$p f$ & -1.85 & 1 & $\Delta p f$ & $-5.28^{* *}$ & 0 \\
$p c$ & -2.22 & 1 & $\Delta p c$ & $-5.85^{* *}$ & 0 \\
$e$ & 4.73 & 4 & $\Delta e$ & $-2.99^{*}$ & 4 \\
$e u$ & -2.58 & 1 & $\Delta e u$ & $-6.99 * *$ & 0 \\
$t o t$ & $-7.05 * *$ & 0 & $\Delta t o t$ & $-16.38^{* *}$ & 0 \\
$\Delta_{12}$ eus & -1.85 & 1 & $\Delta \Delta_{12}$ eus & $-7.07^{* *}$ & 0 \\
$w f p$ & -2.45 & 1 & $\Delta w f p$ & $-6.87^{* *}$ & 0 \\
$w p$ & -2.45 & 2 & $\Delta w p$ & $-3.90^{* *}$ & 0 \\
$m$ & -0.46 & 0 & $\Delta m$ & $-11.66^{* *}$ & 1 \\
$m-p$ & -2.20 & 3 & $\Delta(m-p)$ & $-4.27 * *$ & 3 \\
& & & & & \\
$y$ & -1.49 & 2 & $\Delta y$ & $-3.55^{* *}$ & 1 \\
$a g$ & $-3.73 * *$ & 2 & $\Delta f e r t$ & $-5.85^{* *}$ & 0 \\
& & & $\Delta e n e r g y$ & $-8.31^{* *}$ & 1 \\
& & & & & \\
\hline
\end{tabular}

Note: Seasonal dummies are included in all models. A trend was used when testing the variables in log-levels. * indicates significance at 5 percent, and ** at 1 percent level. 
Table 1: Main components of the CPI

\begin{tabular}{lclc}
\hline Component & Weight & Component & Weight \\
\hline Non-Food & 42.99 & Oils, fats & 2.39 \\
House rent, construction, water, fuel, power & 20.56 & Vegetables & 2.55 \\
Food total & 57.01 & Spices & 1.97 \\
Cereals & 22.54 & Potatoes, other tubers, stems & 4.16 \\
Pulses & 4.31 & Coffee, tea & 4.27 \\
Bread, other prepared food & 1.87 & Otherfood items & 1.23 \\
Meat & 2.82 & Milling charges & 1.17 \\
Milk, cheese, eggs & 1.96 & Food taken away from home & 5.76 \\
\hline
\end{tabular}

Table 2: Cointegration analysis of the monetary sector, April 1999-December 2009

\begin{tabular}{|c|c|c|c|}
\hline \multicolumn{4}{|c|}{ Rank test } \\
\hline Null hypothesis & $\mathrm{r}=0$ & $\mathrm{r} \leq 1$ & $\mathrm{r}=\leq 2$ \\
\hline Eigenvalues & 0.18 & 0.09 & 0.00 \\
\hline Trace statistic & 39.09 & 14.26 & 0.72 \\
\hline$\underline{\text { Probability-value }}$ & 0.003 & 0.08 & 0.40 \\
\hline \multicolumn{4}{|c|}{ Standardized eigenvector $\beta_{i}$} \\
\hline & $m-p$ & $y$ & $\Delta_{12} e u s$ \\
\hline & 1.00 & -0.88 & 1.88 \\
\hline & - & {$[0.08]$} & {$[0.24]$} \\
\hline \multicolumn{4}{|c|}{ Standardized adjustment coefficients $\alpha_{i}$} \\
\hline & $\begin{array}{l}-0.07 \\
{[0.020]}\end{array}$ & $\begin{array}{l}\text { Assumed weakly } \\
\text { exogenous }\end{array}$ & $\begin{array}{l}-0.04 \\
{[0.012]}\end{array}$ \\
\hline
\end{tabular}


Table 3: Cointegration analysis of the external sector, January 2000-December 2009

\begin{tabular}{|c|c|c|c|}
\hline \multicolumn{3}{|c|}{ Rank test } & \\
\hline Null hypothesis & $\mathrm{r}=0$ & $\mathrm{r} \leq 1$ & \\
\hline Eigenvalues & 0.15 & 0.06 & \\
\hline Trace statistic & 26.05 & 7.11 & \\
\hline \multirow[t]{7}{*}{$\underline{\text { Probability-value }}$} & 0.045 & 0.34 & \\
\hline & \multicolumn{3}{|c|}{ Standardized eigenvectors $\beta_{i j}$} \\
\hline & $e+w f p$ & $p c$ & trend \\
\hline & 1.00 & -0.85 & 0.0023 \\
\hline & - & {$[0.14]$} & {$[0.002]$} \\
\hline & \multicolumn{3}{|c|}{ Standardized adjustment coefficients $\alpha_{i j}$} \\
\hline & $\begin{array}{c}0.044 \\
{[0.031]}\end{array}$ & $\begin{array}{c}0.109 \\
{[0.026]}\end{array}$ & \\
\hline \multicolumn{4}{|c|}{ Likelihood ratio test: restricted cointegrated vector: $\left(\beta_{1}+\beta_{2}\right)-\beta_{3}=0, \chi^{2}(2)=12.5[0.002]$} \\
\hline \multicolumn{4}{|c|}{ Likelihood ratio test: with trend: $\left(\beta_{1}+\beta_{2}\right)-\beta_{3}+0.0046$ trend $=0, \chi^{2}(1)=0.43[0.51]$} \\
\hline
\end{tabular}

Note: The VAR includes two lags on each variable and centered seasonal dummy variables. Standard errors are in brackets. 
Table 4: Parsimonious inflation models for Ethiopia, January 2000-December 2009

\begin{tabular}{|c|c|c|c|c|c|}
\hline Explanatory variables & & $\begin{array}{l}\text { Model 1: } \\
\text { Cereals } \\
\Delta p c\end{array}$ & $\begin{array}{l}\text { Model 2: } \\
\text { Food } \\
\Delta p f\end{array}$ & $\begin{array}{l}\text { Model 3: } \\
\text { Nonfood } \\
\Delta p n f\end{array}$ & $\begin{array}{l}\text { Model 4: } \\
\text { CPI } \\
\Delta p\end{array}$ \\
\hline EC-Monetary sector & {$\left[(m-p)-0.88 y+1.88 \Delta_{12} \text { eus }\right]_{t-1}$} & $\begin{array}{c}-0.037 \\
(-1.44)\end{array}$ & $\begin{array}{l}0.006 \\
(0.005)\end{array}$ & $\begin{array}{l}0.003 \\
(0.38)\end{array}$ & $\begin{array}{c}-0.011 \\
(-1.53)\end{array}$ \\
\hline EC-External food sector & {$[e+w f p-p c+0.0046 \text { trend }]_{t-1}$} & $\begin{array}{l}0.105^{* *} \\
(7.99)\end{array}$ & $\begin{array}{l}0.065^{* *} \\
(8.31)\end{array}$ & & $\begin{array}{l}0.037 * * \\
(7.73)\end{array}$ \\
\hline EC-External non- food sector & {$[e+w p-p n f-\text { hptrend }]_{t-1}$} & & & $\begin{array}{l}0.086 * * \\
(3.88)\end{array}$ & $\begin{array}{r}0.050 * \\
(2.23)\end{array}$ \\
\hline Agricultural output gap & $a g_{t-1}$ & $\begin{array}{l}-0.238^{* *} \\
(-7.79)\end{array}$ & $\begin{array}{l}-0.108 * * \\
(-6.64)\end{array}$ & & $\begin{array}{c}-0.063 * * \\
(-6.53)\end{array}$ \\
\hline Lagged cereal inflation & $\Delta p c_{t-5}$ & $\begin{array}{l}-0.186 * * \\
(-3.39)\end{array}$ & & & \\
\hline Lagged non-food inflation & $\Delta p n f_{t-4}$ & & & $\begin{array}{l}0.273 * * \\
(2.98)\end{array}$ & \\
\hline Lagged inflation & $\Delta p_{t-10}$ & & & & $\begin{array}{l}0.15^{* *} \\
(3.79)\end{array}$ \\
\hline Energy price inflation & $\Delta e n e r g y_{t-3}$ & & & & $\begin{array}{l}0.026 * \\
(2.54)\end{array}$ \\
\hline Energy price inflation & $\Delta e n e r g y_{t-4}$ & & $\begin{array}{l}0.046 * * \\
(2.68)\end{array}$ & & \\
\hline Energy price inflation & $\Delta e n e r g y_{t-8}$ & $\begin{array}{l}0.091 * * \\
(3.04)\end{array}$ & $\begin{array}{l}0.034 \\
(1.98)\end{array}$ & & \\
\hline Money growth & $\Delta m_{t-9}$ & $\begin{array}{c}0.114 \\
(0.67)\end{array}$ & $\begin{array}{l}0.125 \\
(1.26)\end{array}$ & $\begin{array}{l}0.234 * * \\
(3.11)\end{array}$ & $\begin{array}{l}0.123^{* *} \\
(2.04)\end{array}$ \\
\hline World food price inflation & $\Delta w f p_{t-12}$ & $\begin{array}{l}0.139 * * \\
(2.77)\end{array}$ & $\begin{array}{l}0.113 * * \\
(3.60)\end{array}$ & & \\
\hline Birr-euro exchange rate & $\Delta e_{t-11}$ & & & & $\begin{array}{l}0.064 * \\
(2.03)\end{array}$ \\
\hline Indicator for Food CPI ${ }^{\mathrm{a}}$ & $\begin{array}{l}2000: 1=1,2008: 3=1, \\
2008: 5=1,2008: 6=2, \\
2008 ; 7=1.5,2008: 12=-1\end{array}$ & $\begin{array}{c}0.094^{* *} \\
(11.30)\end{array}$ & $\begin{array}{l}0.055^{* *} \\
(11.20)\end{array}$ & & \\
\hline Indicator for $\mathrm{CPI}^{\mathrm{a})}$ & & & & & $\begin{array}{l}0.028^{* *} \\
(13.5)\end{array}$ \\
\hline Constant $^{\text {b) }}$ & & $\begin{array}{c}0.126 \\
(1.65)\end{array}$ & $\begin{array}{l}0.010 \\
(0.68)\end{array}$ & $\begin{array}{c}-0.009 \\
(-0.30)\end{array}$ & $\begin{array}{c}0.041 \\
(1.82)\end{array}$ \\
\hline Seasonal dummies ${ }^{\text {b) }}$ & & Yes & Yes & Yes & Yes \\
\hline
\end{tabular}

Note: t-values in parenthesis. * indicates significance at 5 percent level and $* *$ significance at 1 percent level.

a) The indexes for the dummies were constructed by running the dummy saturation procedure in Autometrics. The weights are based on the coefficients from the general models. The weights are 2000:1=1, 2008:3=1, 2008:5=1, 2008:6=2, 2008:7=1.5, and 2008:12=-1 for food CPI, and 2000:1=1, 2006:5 =1.4, 2008:3=1.6, 2008:5=1.7, 2008:6=3, 2008:7=1.7 and 2008:12=-1.4 for CPI.

b) The constant and seasonal dummies are fixed when running Autometrics and thus remain in the models by force. 
Table 5: Diagnostic tests for parsimonious inflation models, January 2000-December 2009

\begin{tabular}{|c|c|c|c|c|c|c|}
\hline & AR 1-7 & ARCH 1-7 & Heterosced. & Normality & RESET & $\mathrm{R}^{2}$ \\
\hline Model & 1: $\mathrm{F}(7,93)$ & $=F(7,106)$ & $=F(27,92)$ & $=\chi^{2} \quad$ (2) & $\mathrm{F}(2,98)$ & $=0.85$ \\
\hline Cereals & $1.41[0.21]$ & $0.39[0.90]$ & $1.1[0.35]$ & $0.41[0.81]$ & 0.39 [0.67] & \\
\hline Model 2 & 2: $F(7,95)$ & $=F(7,106)$ & $=F(23,96)$ & $=\chi^{2} \quad(2)=$ & $\mathrm{F}(2,100)$ & $=0.82$ \\
\hline Food & $1.23[0.29]$ & $0.82[0.57]$ & $1.21[0.25]$ & $3.17[0.20]$ & $1.21[0.25]$ & \\
\hline Model & 3: $F(7,97)$ & $=F(7,106)$ & $=F(19,100)$ & $=\chi^{2} \quad(2)=$ & $\mathrm{F}(2,102)$ & $=0.34$ \\
\hline Non-food & $1.15[0.33]$ & $0.76[0.62]$ & $1.52[0.09]$ & $2.32[0.31]$ & $0.24[0.79]$ & \\
\hline Model 4 & 4: $F(7,92)$ & $=F(7,106)$ & $=F(29,90)$ & $=\chi^{2} \quad(2)=$ & $\mathrm{F}(2,87)$ & $=0.88$ \\
\hline CPI & $1.74[0.11]$ & $0.48[0.84]$ & $1.05[0.41]$ & $3.81[0.15]$ & $0.18[0.83]$ & \\
\hline
\end{tabular}

Note: AR is a test for serial autocorrelation for up to seven lags, ARCH is a test for autoregressive heteroscedasticity, RESET is a test for non-linearity. Probability values in brackets. See Hendry and Nielsen (2007) for details.

Table 6: Omitted variables tests, January 2000-December 2009

\begin{tabular}{|c|c|c|c|c|c|c|}
\hline & & $\begin{array}{l}\text { Model } \\
\text { Cereals }\end{array}$ & $\begin{array}{l}\text { 1: } \begin{array}{l}\text { Model } \\
\text { Food }\end{array}\end{array}$ & $\begin{array}{l}\text { 2: } \text { Model } 3 \\
\text { Non-food }\end{array}$ & $\begin{array}{l}\text { Model } \\
\text { CPI }\end{array}$ & 4: \\
\hline $\begin{array}{l}\text { Monetary } \\
\text { overhang }\end{array}$ & {$\left[(m-p)-y^{*}+v^{*}\right]_{t-1}$} & $\begin{array}{l}\mathrm{F}(1,104) \\
0.21[0.64]\end{array}$ & $\begin{aligned}= & \mathrm{F}(1,100) \\
& 3.65[0.06]\end{aligned}$ & $\begin{aligned}= & \mathrm{F}(1,104) \\
& 1.61[0.21]\end{aligned}$ & $\begin{aligned}= & \mathrm{F}(1,99) \\
& 1.04[0.31]\end{aligned}$ & $=$ \\
\hline $\begin{array}{l}\text { EC-Monetary } \\
\text { sector } 2\end{array}$ & {$\left[\begin{array}{l}(m-p)-0.85 y+ \\
1.34 \Delta_{12} \text { eus }+0.52 \Delta_{12} p\end{array}\right]_{t-1}$} & $\begin{array}{l}F(1,104) \\
0.15[0.69]\end{array}$ & $\begin{aligned}= & \mathrm{F}(1,100) \\
& 0.50[0.48]\end{aligned}$ & $\begin{aligned}= & \mathrm{F}(1,104) \\
& 1.36[0.25]\end{aligned}$ & $\begin{aligned}= & F(1,99) \\
& 1.89[0.17]\end{aligned}$ & $=$ \\
\hline Reserve money & $\sum_{i=1}^{i=12} \Delta h p m_{t-i}$ & $\begin{array}{l}\mathrm{F}(12,90) \\
1.01[0.44]\end{array}$ & $\begin{aligned}= & \mathrm{F}(12,89) \\
& 0.73[0.71]\end{aligned}$ & $\begin{aligned}= & F(12,93) \\
& 0.49[0.91]\end{aligned}$ & $\begin{aligned}= & \mathrm{F}(12,88) \\
& 0.66[0.78]\end{aligned}$ & $=$ \\
\hline
\end{tabular}

Note: Probability values in brackets. 
Table 7: Models without dummy variables but with HAC standard errors, January 2000-December 2009.

\begin{tabular}{|c|c|c|c|c|}
\hline Explanatory variables & & $\begin{array}{l}\text { Model 1: } \\
\text { Cereals } \\
\Delta p c\end{array}$ & $\begin{array}{l}\text { Model 2: } \\
\text { Food } \\
\Delta p f\end{array}$ & $\begin{array}{l}\text { Model 4: } \\
\text { CPI } \\
\Delta p\end{array}$ \\
\hline EC-Monetary sector & {$\left[(m-p)-0.88 y+1.88 \Delta_{12} e u s\right]_{t-1}$} & $\begin{array}{c}-0.082 \\
(-1.51)\end{array}$ & $\begin{array}{c}-0.015 \\
(-0.53)\end{array}$ & $\begin{array}{l}-0.025 \\
(-1.63)\end{array}$ \\
\hline EC-External food sector & {$[e+w f p-p c+0.0046 t r e n d]_{t-1}$} & $\begin{array}{l}0.163 * * \\
(4.66)\end{array}$ & $\begin{array}{l}0.095 * * \\
(4.85)\end{array}$ & $\begin{array}{l}0.053 * * \\
(4.96)\end{array}$ \\
\hline EC-External non- food sector & {$[e u+w p-p n f-\text { hptrend }]_{t-1}$} & & & $\begin{array}{l}0.166^{* *} \\
(3.69)\end{array}$ \\
\hline Agricultural output gap & $a g_{t-1}$ & $\begin{array}{l}-0.251 * * \\
(-4.90)\end{array}$ & $\begin{array}{l}-0.101 * * \\
(-4.01)\end{array}$ & $\begin{array}{l}-0.063 * * \\
(-4.02)\end{array}$ \\
\hline Lagged cereal inflation & $\Delta p c_{t-5}$ & $\begin{array}{l}-0.245^{* *} \\
(-3.07)\end{array}$ & & \\
\hline Lagged inflation & $\Delta p_{t-10}$ & & & $\begin{array}{l}0.27 * * \\
(3.54)\end{array}$ \\
\hline Energy price inflation & $\Delta e n e r g y_{t-3}$ & & & $\begin{array}{l}0 . .015^{*} \\
(2.54)\end{array}$ \\
\hline Energy price inflation & $\Delta e n e r g y_{t-4}$ & & $\begin{array}{l}0.078 * * \\
(3.29)\end{array}$ & \\
\hline Energy price inflation & $\Delta e n e r g y_{t-8}$ & $\begin{array}{l}0.179 * * \\
(3.00)\end{array}$ & $\begin{array}{l}0.083 * \\
(2.36)\end{array}$ & \\
\hline Money growth & $\Delta m_{t-9}$ & $\begin{array}{c}0.349 \\
(1.61)\end{array}$ & $\begin{array}{l}0.266^{*} \\
(2.09)\end{array}$ & $\begin{array}{l}0.179 * \\
(2.07)\end{array}$ \\
\hline World food price inflation & $\Delta w f p_{t-12}$ & $\begin{array}{l}0.133^{*} \\
(2.00)\end{array}$ & $\begin{array}{l}0.131 * * \\
(2.57)\end{array}$ & \\
\hline Birr-euro exchange rate & $\Delta e_{t-11}$ & & & $\begin{array}{r}0.028 \\
(0.06)\end{array}$ \\
\hline Constant $^{\mathrm{a})}$ & & $\begin{array}{c}0.266 \\
(1.62)\end{array}$ & $\begin{array}{r}0.057 \\
(0.70)\end{array}$ & $\begin{array}{r}0.084 \\
(1.82)\end{array}$ \\
\hline Seasonal dummies ${ }^{\text {a) }}$ & & Yes & Yes & Yes \\
\hline & $\begin{array}{l}\text { Model 1: } \\
\text { Cereals }\end{array}$ & $\begin{array}{l}\text { Model 2: } \\
\text { Food }\end{array}$ & & $\begin{array}{l}\text { Model 4: } \\
\text { CPI }\end{array}$ \\
\hline $\mathrm{R}^{2}$ & 0.66 & 0.65 & & 0.66 \\
\hline AR 1-7 & $\begin{array}{l}\mathrm{F}(7,94)=2.09 \\
{[0.06]^{*}}\end{array}$ & $\begin{array}{l}\mathrm{F}(7,94)=2.73 \\
{[0.01]^{*}}\end{array}$ & & $\begin{array}{l}F(7,93)=1.62 \\
{[0.13]}\end{array}$ \\
\hline Heteroscedasticity & $\begin{array}{l}\mathrm{F}(25,94)=2.08 \\
{[0.00]^{* *}}\end{array}$ & $\begin{array}{l}\mathrm{F}(25,94)= \\
1.61[0.05]\end{array}=$ & & $\begin{array}{l}\mathrm{F}(27,92)= \\
2.25[0.00]^{* *}\end{array}$ \\
\hline Normality & $\begin{array}{l}\chi^{2}(2)=18.1 \\
{[0.00]^{* *}}\end{array}$ & $\begin{array}{l}\chi^{2}(2)=19.5 \\
{[0.00]^{* *}}\end{array}$ & & $\begin{array}{l}\chi^{2}(2)=20.5 \\
{[0.00]^{* *}}\end{array}$ \\
\hline
\end{tabular}

Note: t-values in parenthesis. * indicates significance at 5 percent level and $* *$ significance at 1 percent level. See Table 5 for description of the tests.

a) The constant and seasonal dummies are fixed when running Autometrics and thus remain in the models by force. 
Figure 1: Annual CPI inflation and its major components, January 1999-July 2010

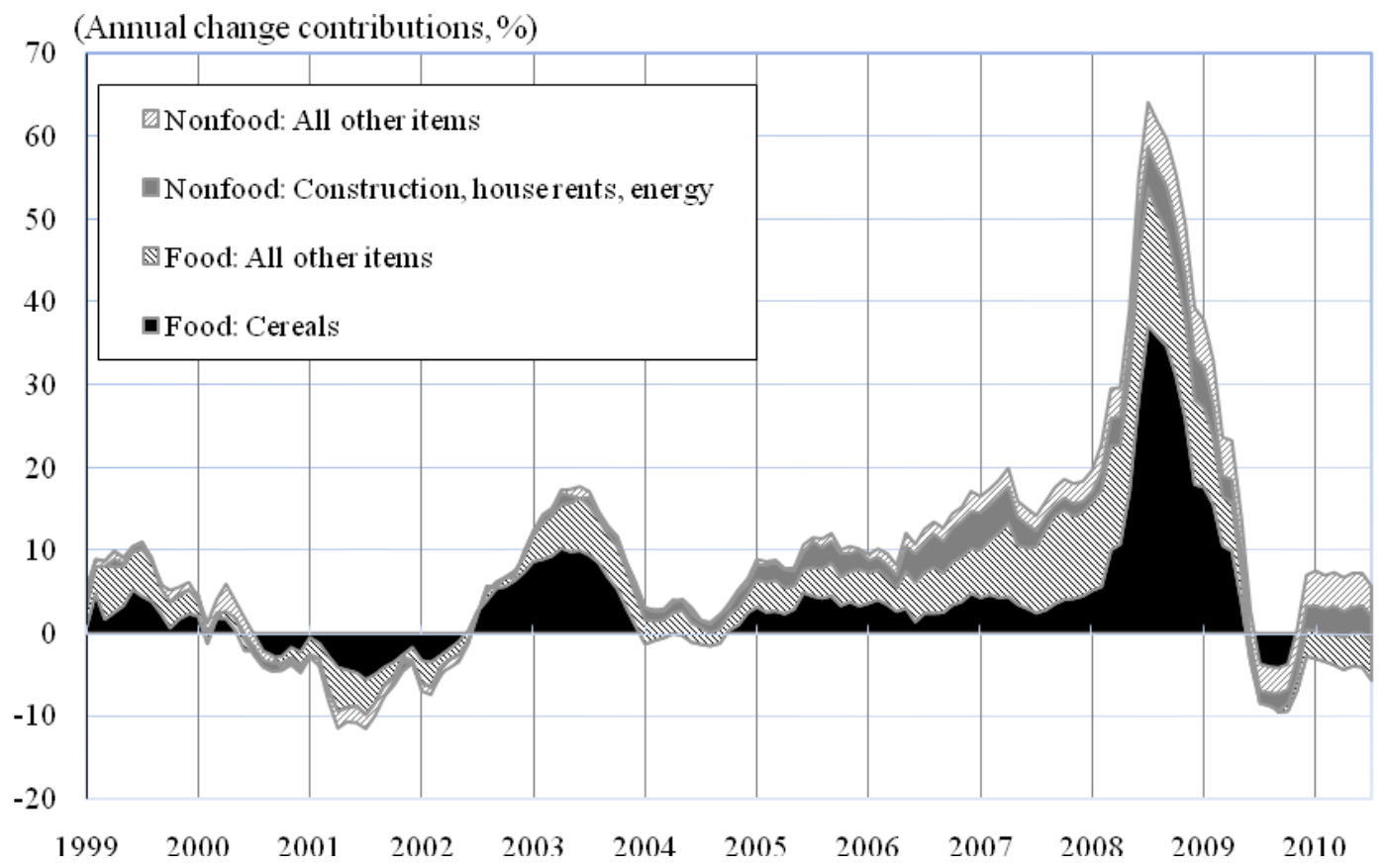

Figure 2: Annual food inflation and its major components, January 1999-July 2010

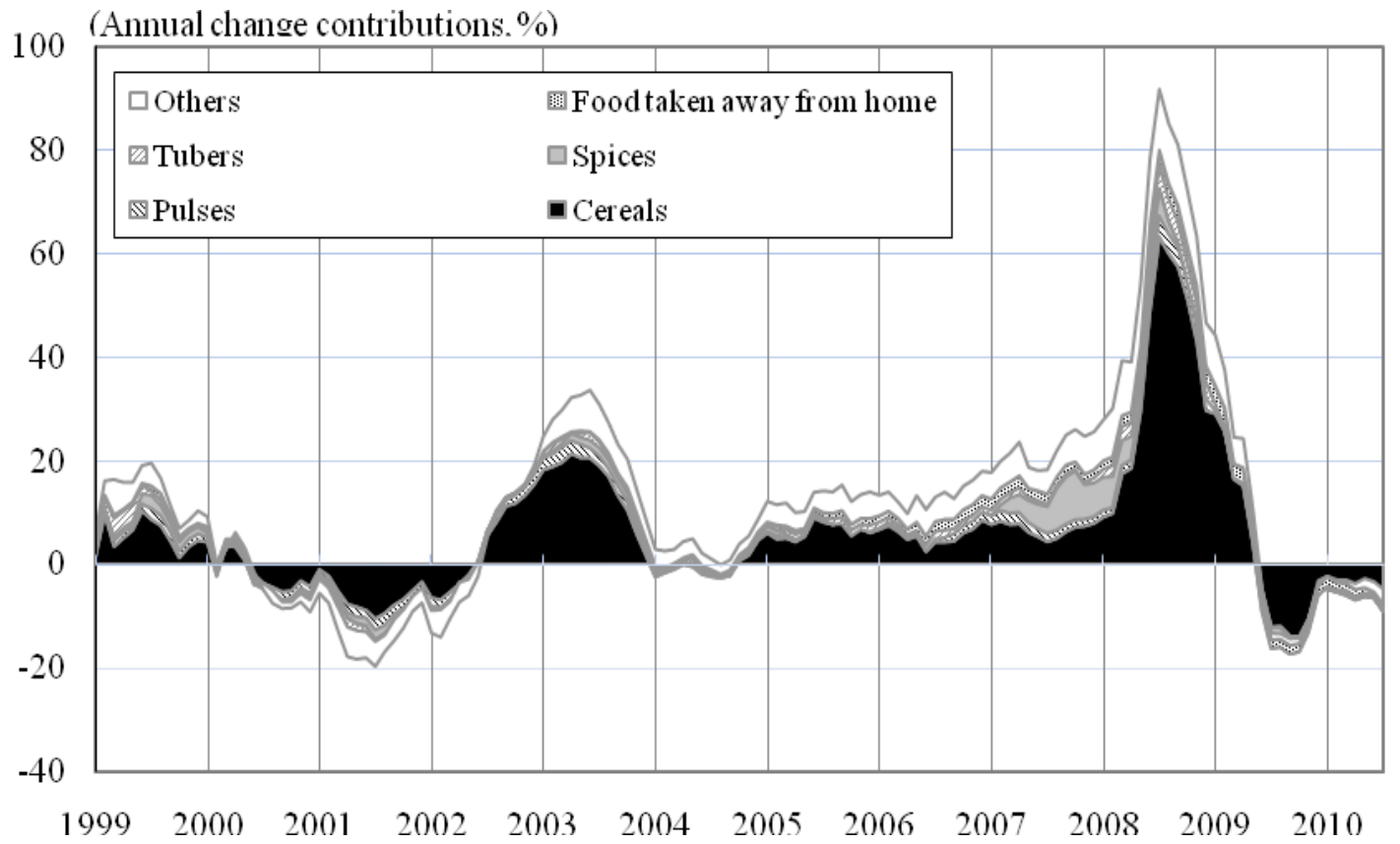


Figure 3: The log of monthly velocity, $y-(m-p)$

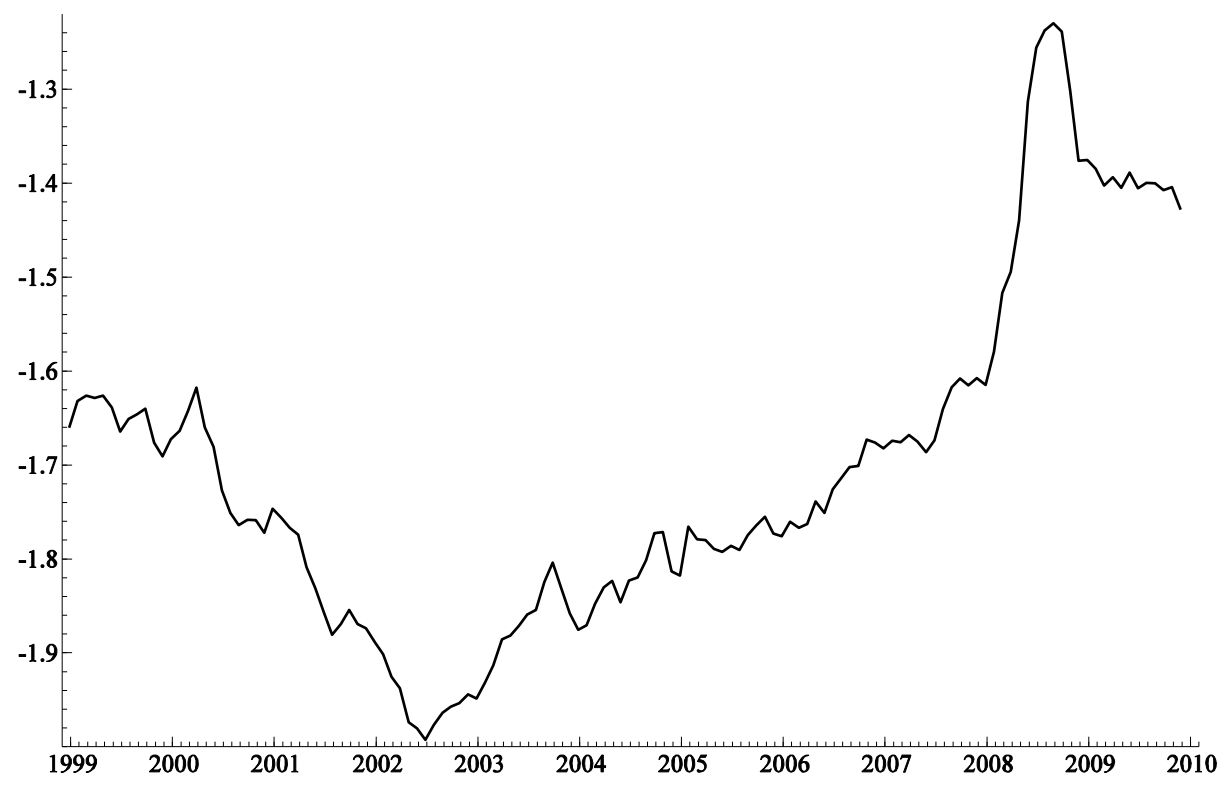

Figure 4: Money demand cointegrating vector, $(m-p)-0.86 y+1.85 \Delta_{12}$ eus.

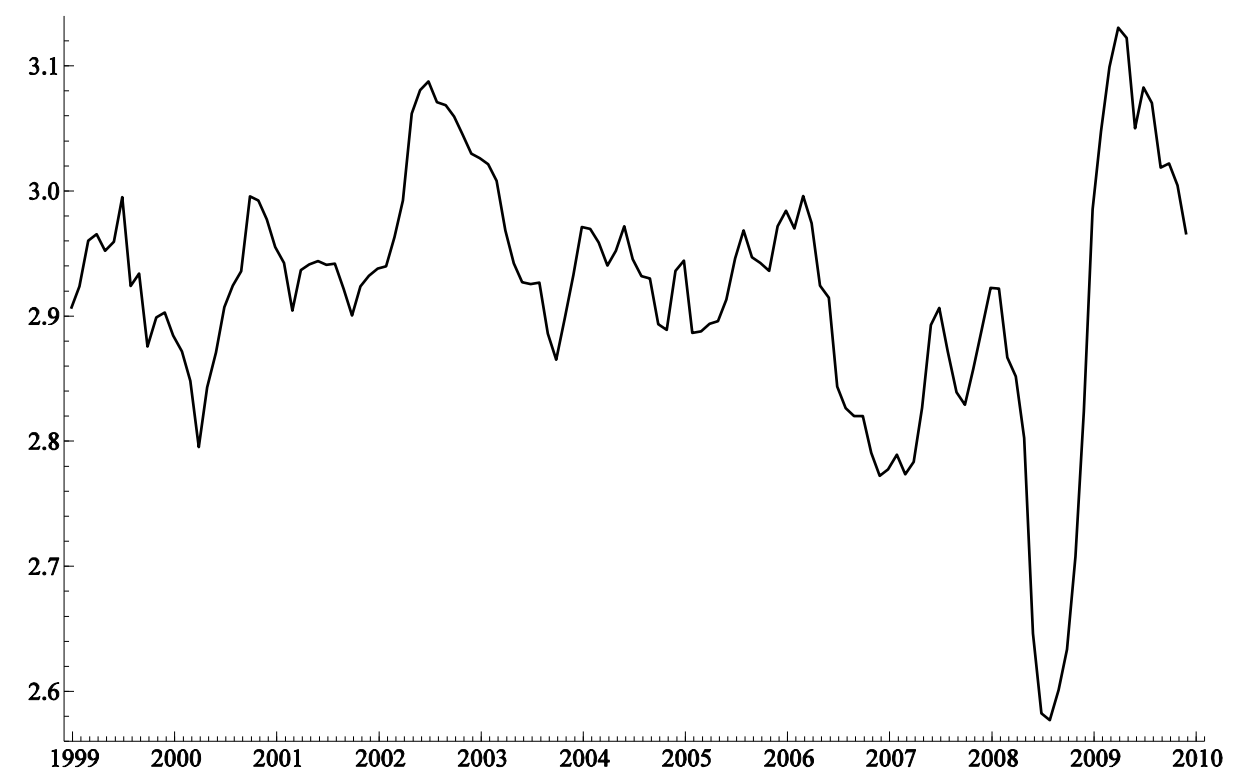


Figure 5: Monetary overhang, $(m-p)-y^{*}+v^{*}$.

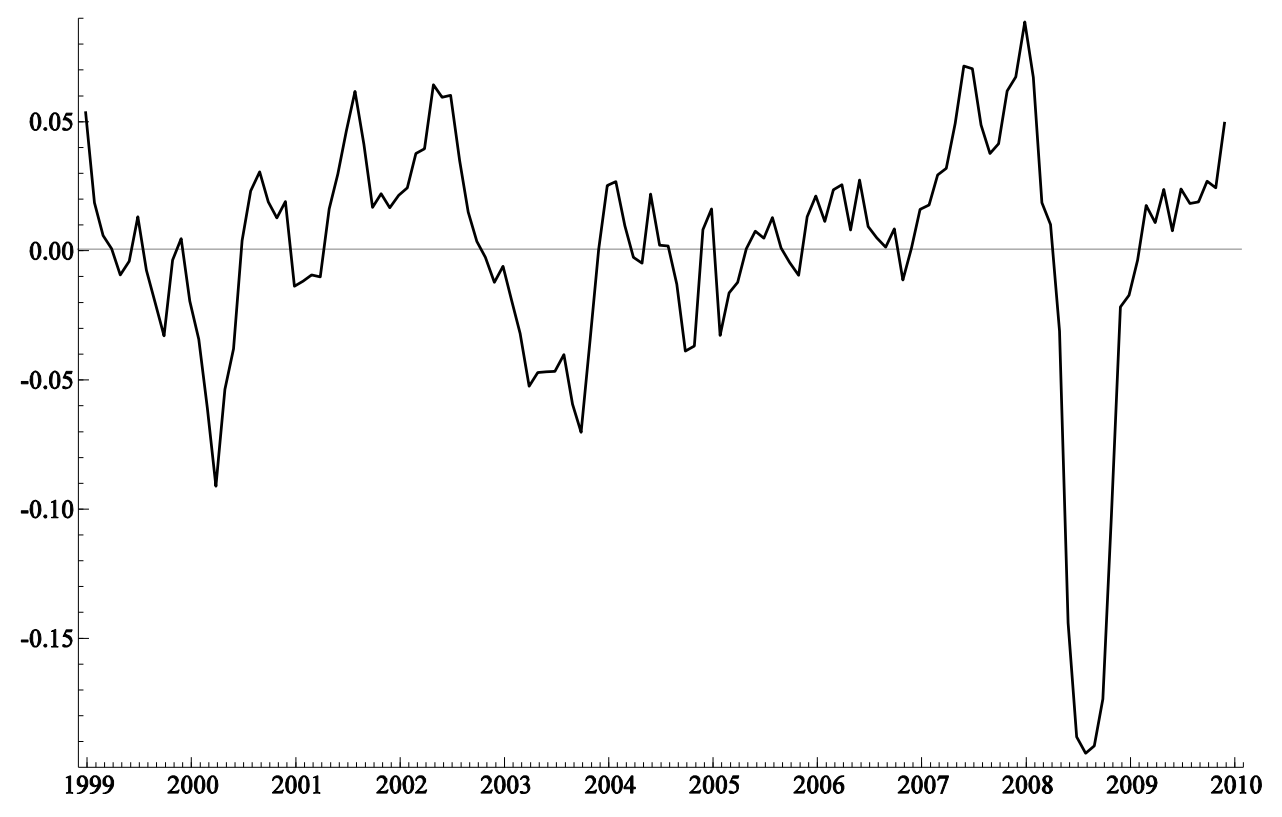

Figure 6: Log of cereal prices minus exchange rate, $p c-e$, (left axis)and world food prices, wfp, (right axis)

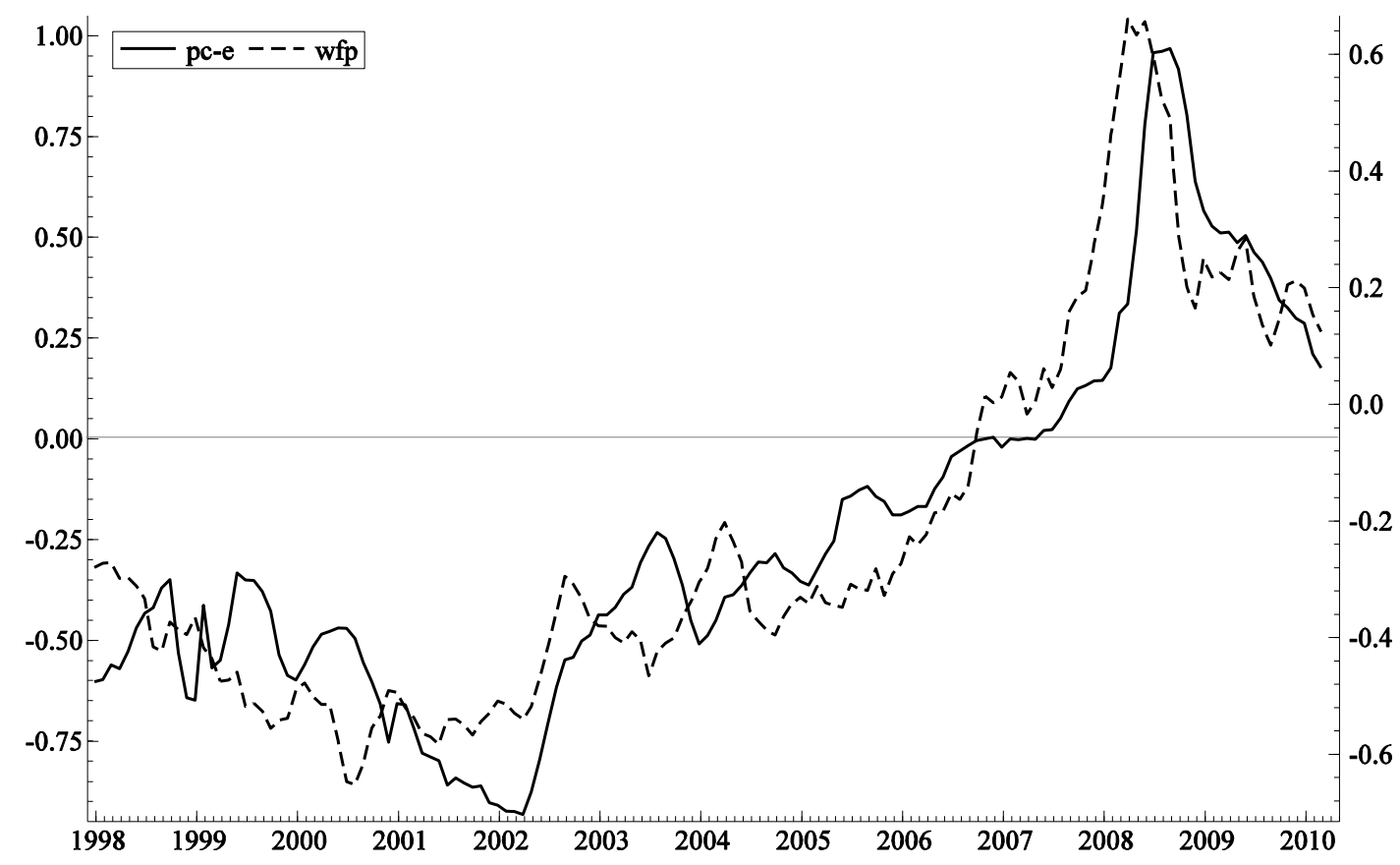


Figure 7: $\log$ of relative price indexes for food, $e+w f p-p c$

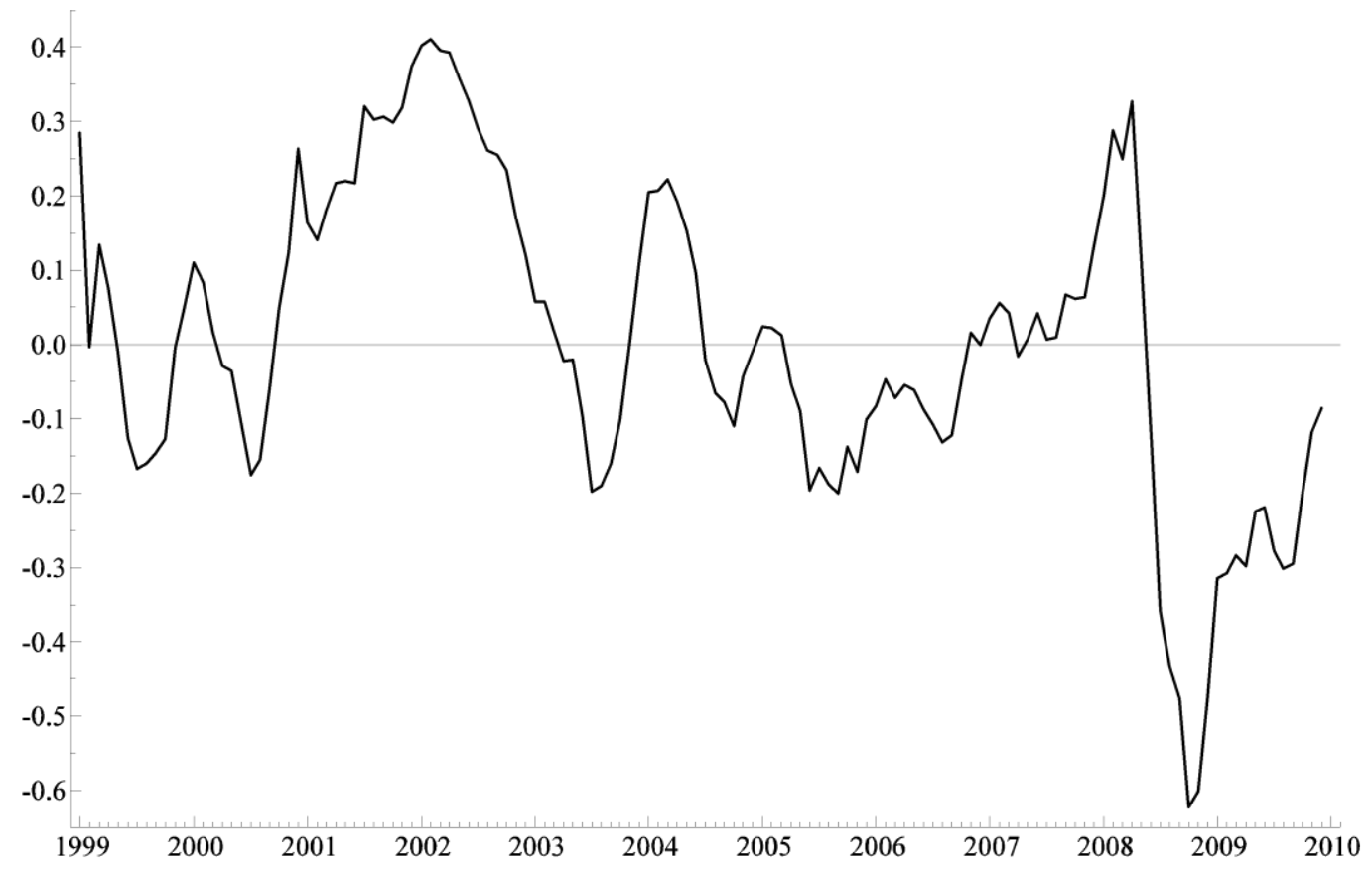

Figure 8: Log of relative price indexes for non-food, $e u+w p-p n f$

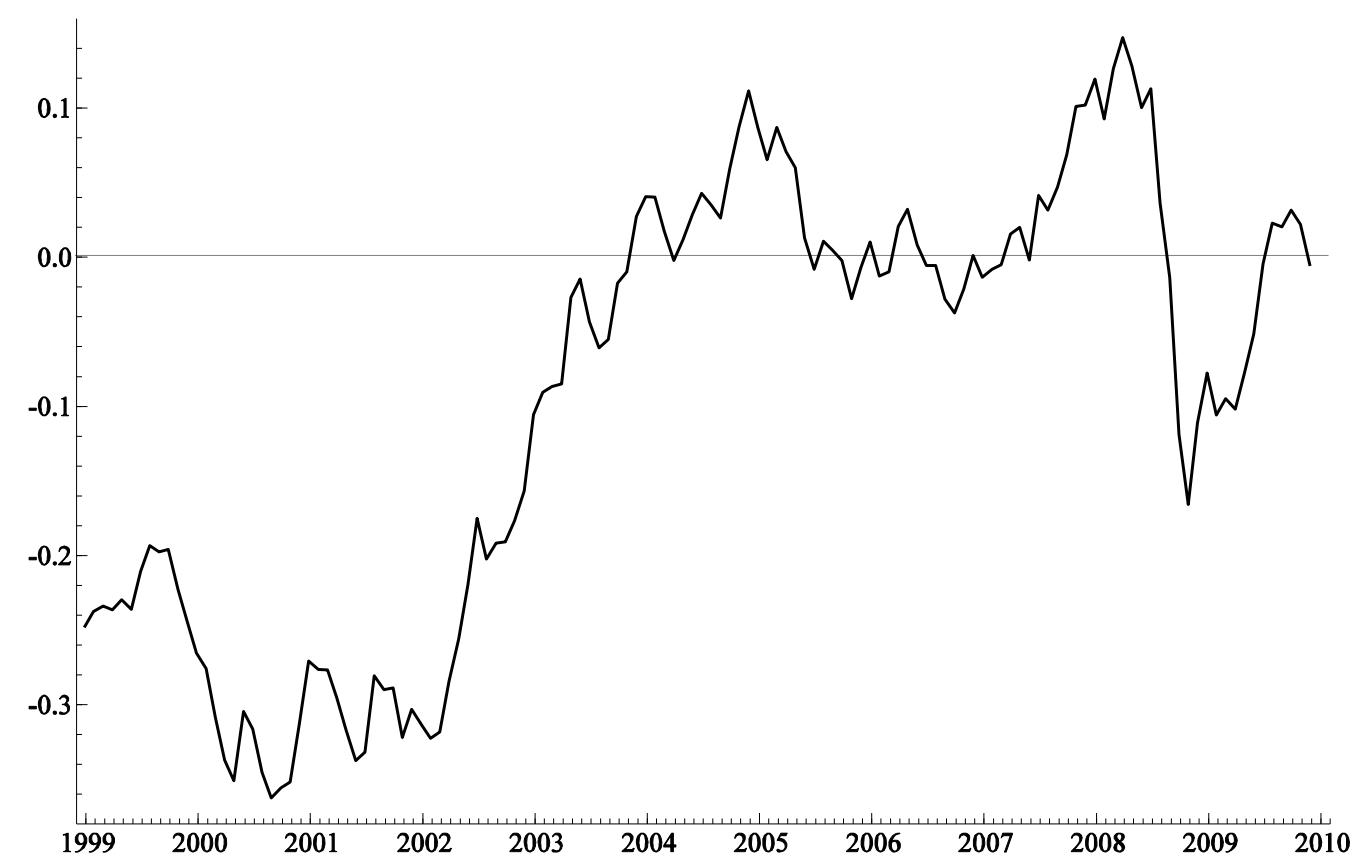


Figure 9: Deviation from long-run equilibrium non-food relative price, $(e+w p-p n f)-$ trend.

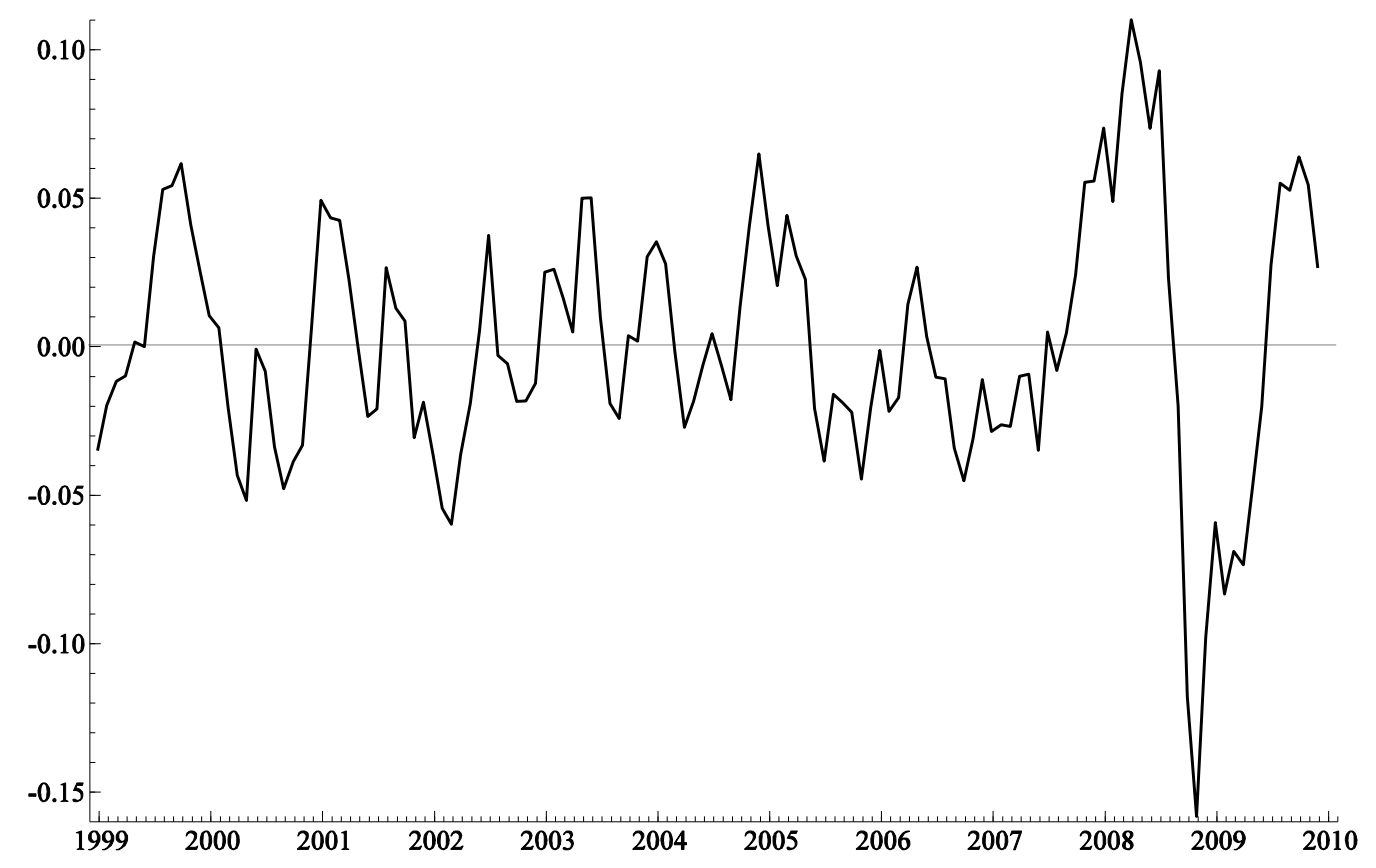

Figure 10: The agricultural output gap (left axis) and annual inflation (right axis) (in \%)

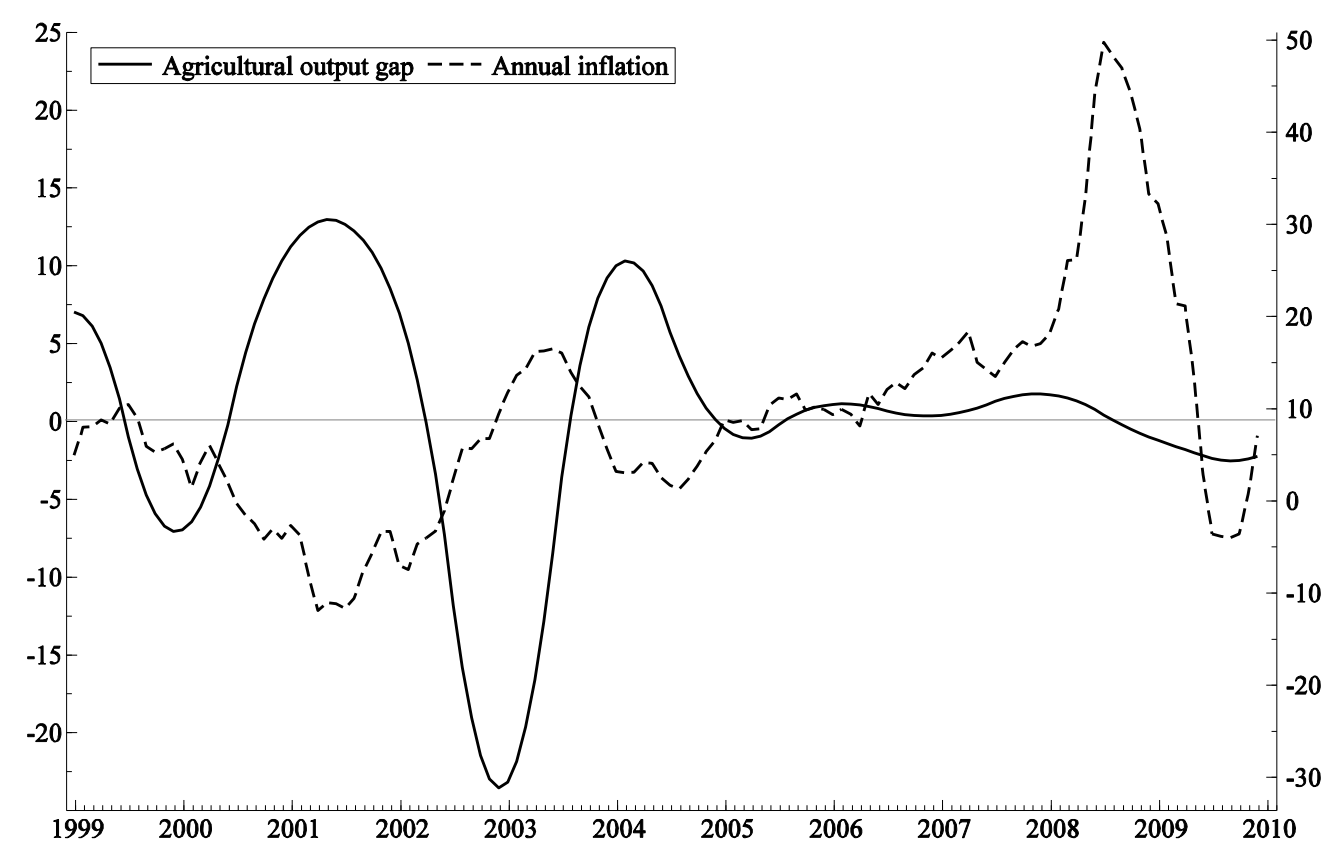


Figure 11: Chow tests for the cereal price model, 2001:1-2009:12
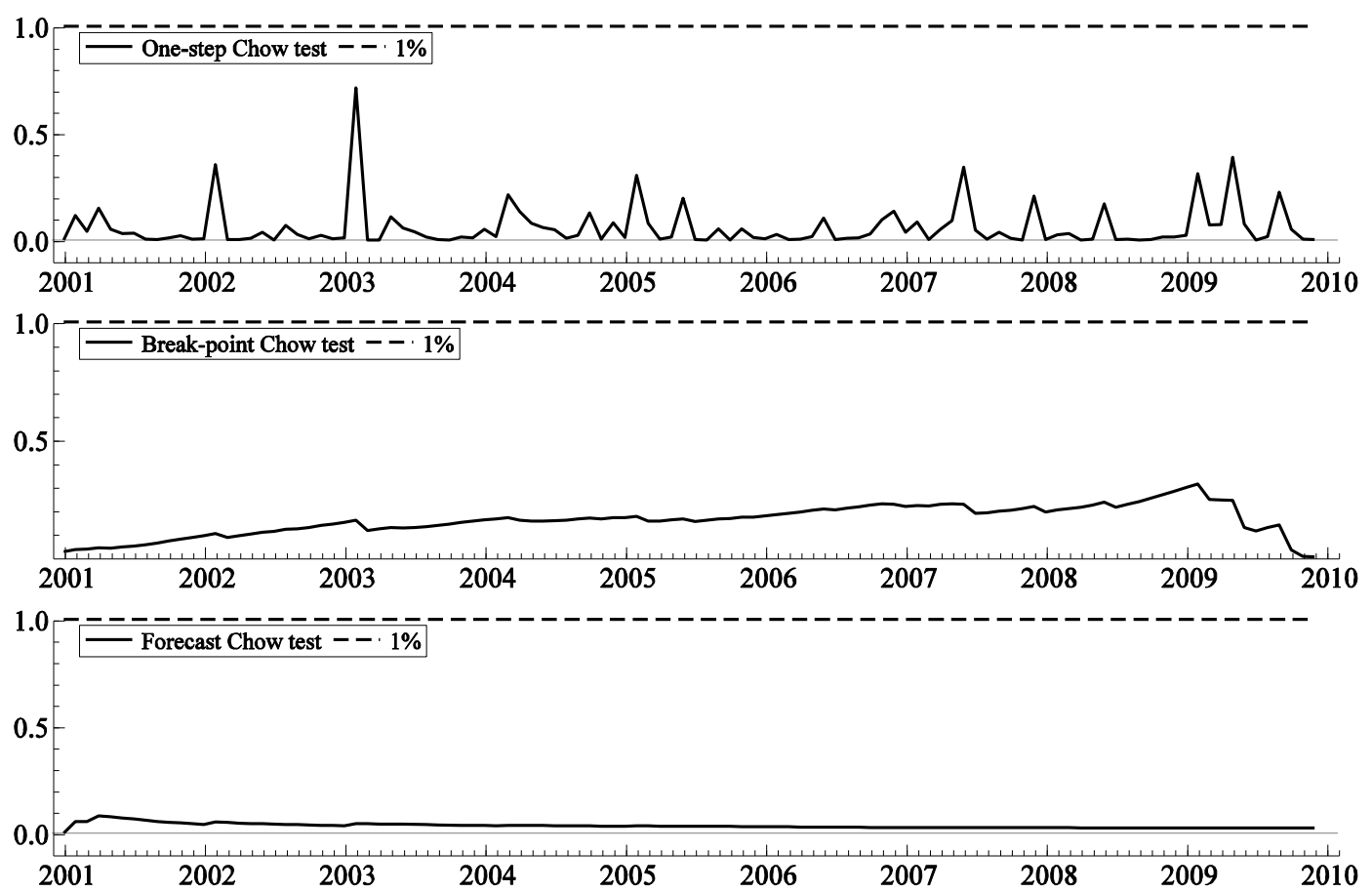

Note: The straight line at 1.0 is the one percent significance level. The null hypothesis in the Onestep Chow is that the last observation comes from the same model as the others. The Break point and Prediction Chows are sequences of tests where the number of observations added are decreasing and increasing, respectively. See Hendry and Nielsen, 2007, Chapter 13, for details. The model was estimated with data from 1999:1, using 24 initial observations.

Figure 12: Recursive estimates of selected coefficients in the food inflation model, 2001:1-2009:12

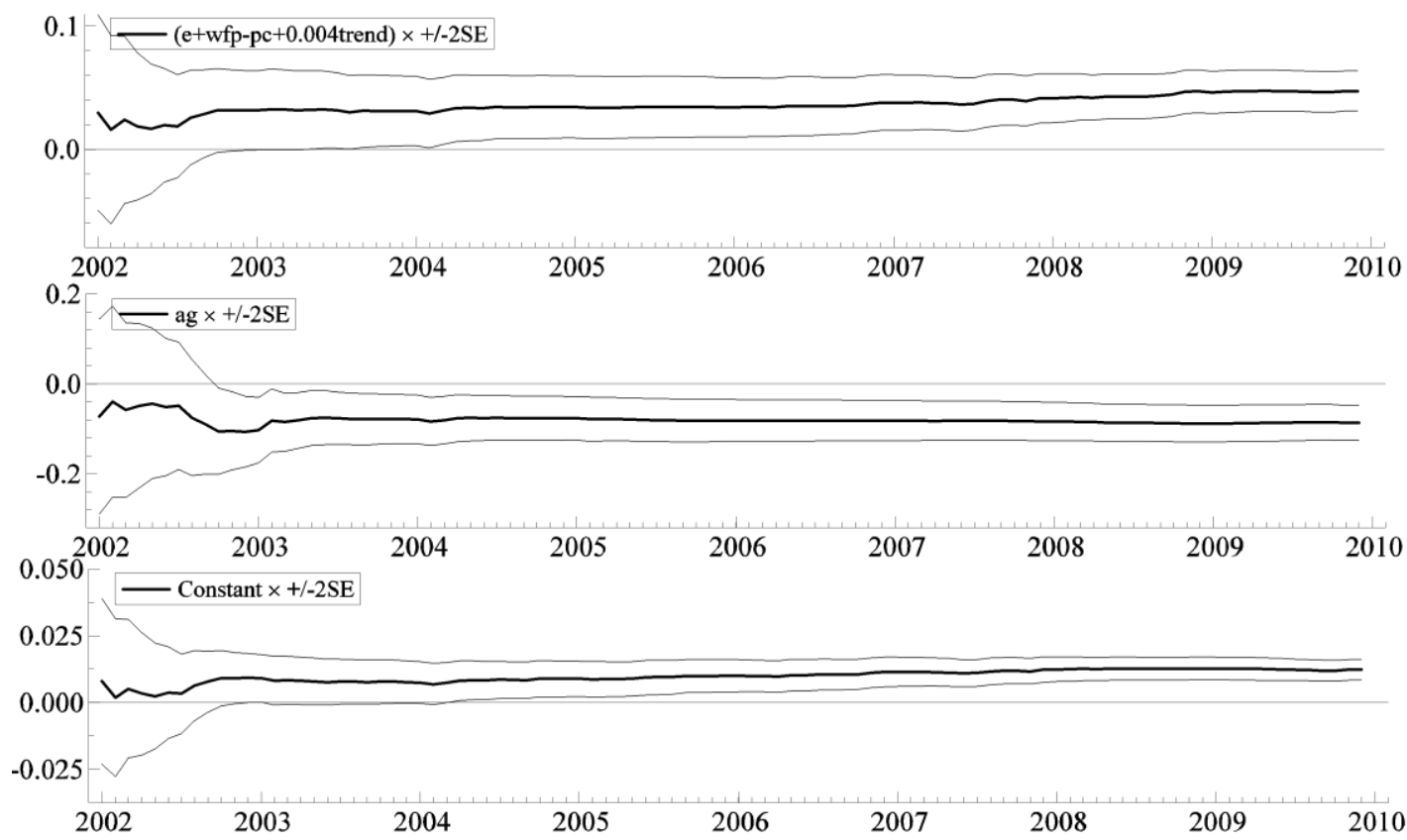

Note: The model was estimated with data from 1999:1, using 36 initial observations. 
Figure 13: Chow tests for the food price model, January 2001-December 2009
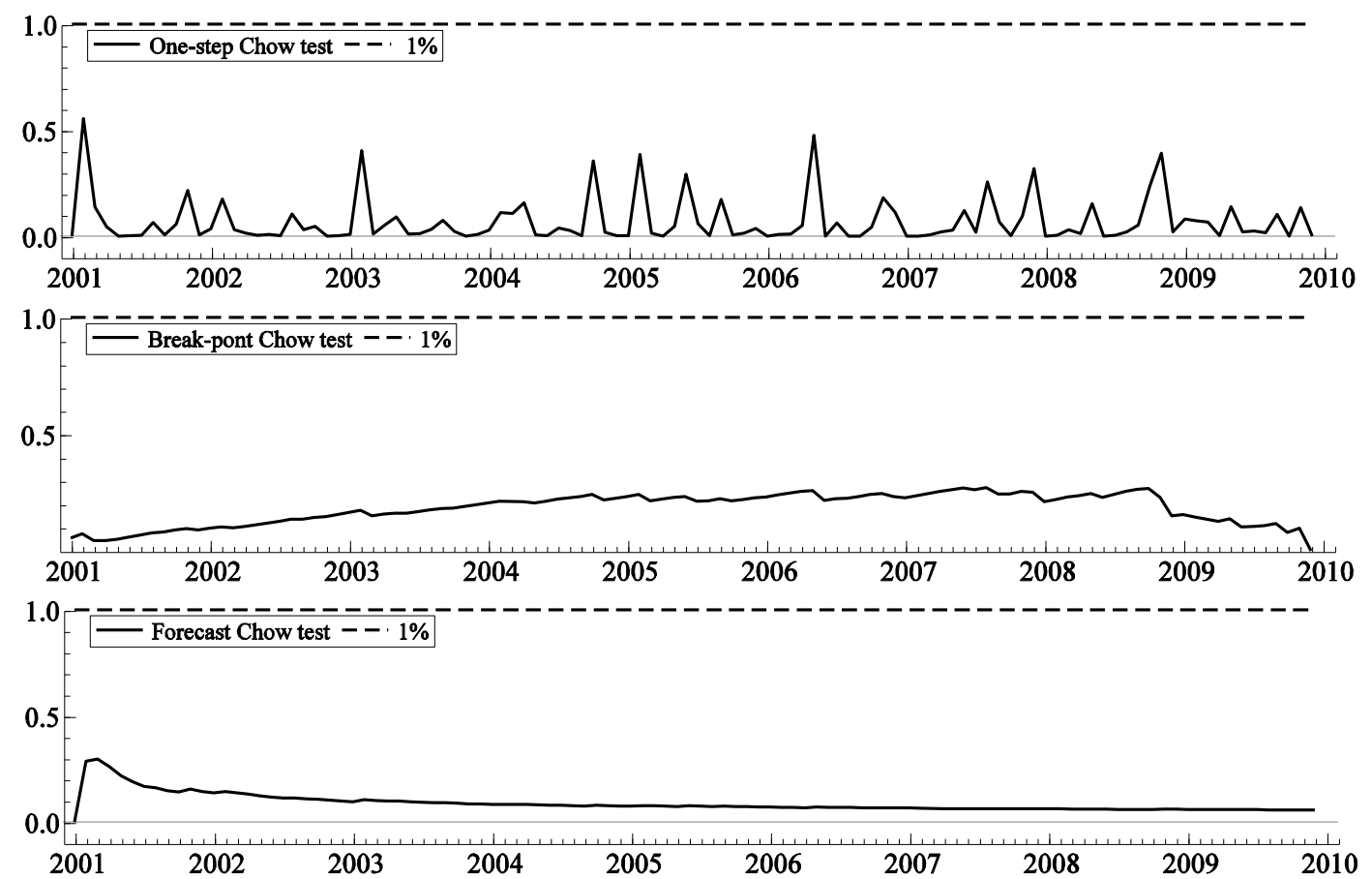

Note: See Figure 11.

Figure 14: Food price, exchange rate and world food price indexes, January 2004-December 2009

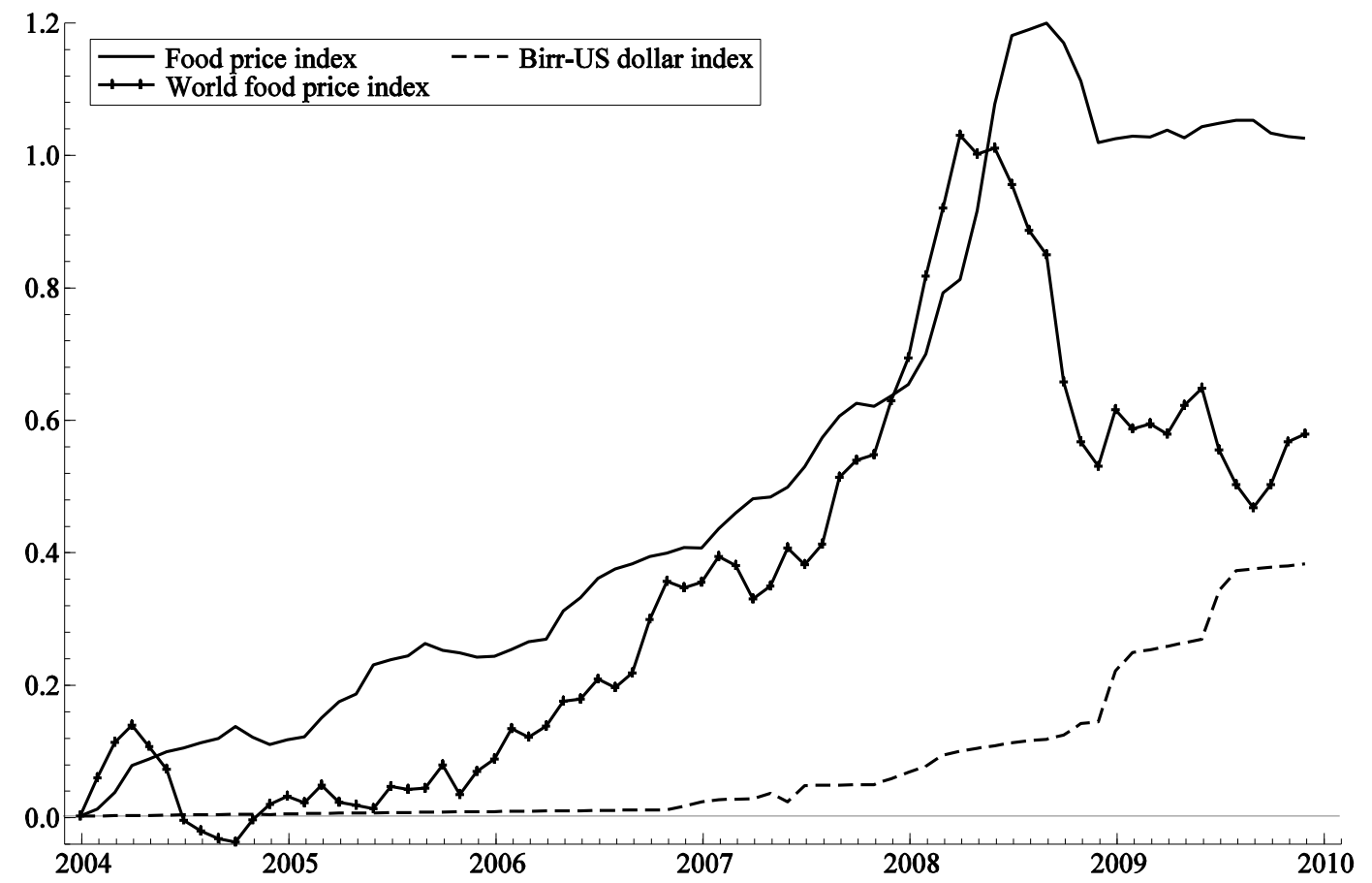

Note: The calculation is carried out by assuming that $p f=e+w f p$ in the long run and that $p f$ and $e+w f p$ have the same value in January 2004, i.e. zero. The domestic food price $p f$ would then follow the exchange rate if the world food price was constant and it would follow the world food price index if the exchange rate was constant. 
Figure 15: Annual cereal price, food price and CPI inflation, January 2008-December 2012.

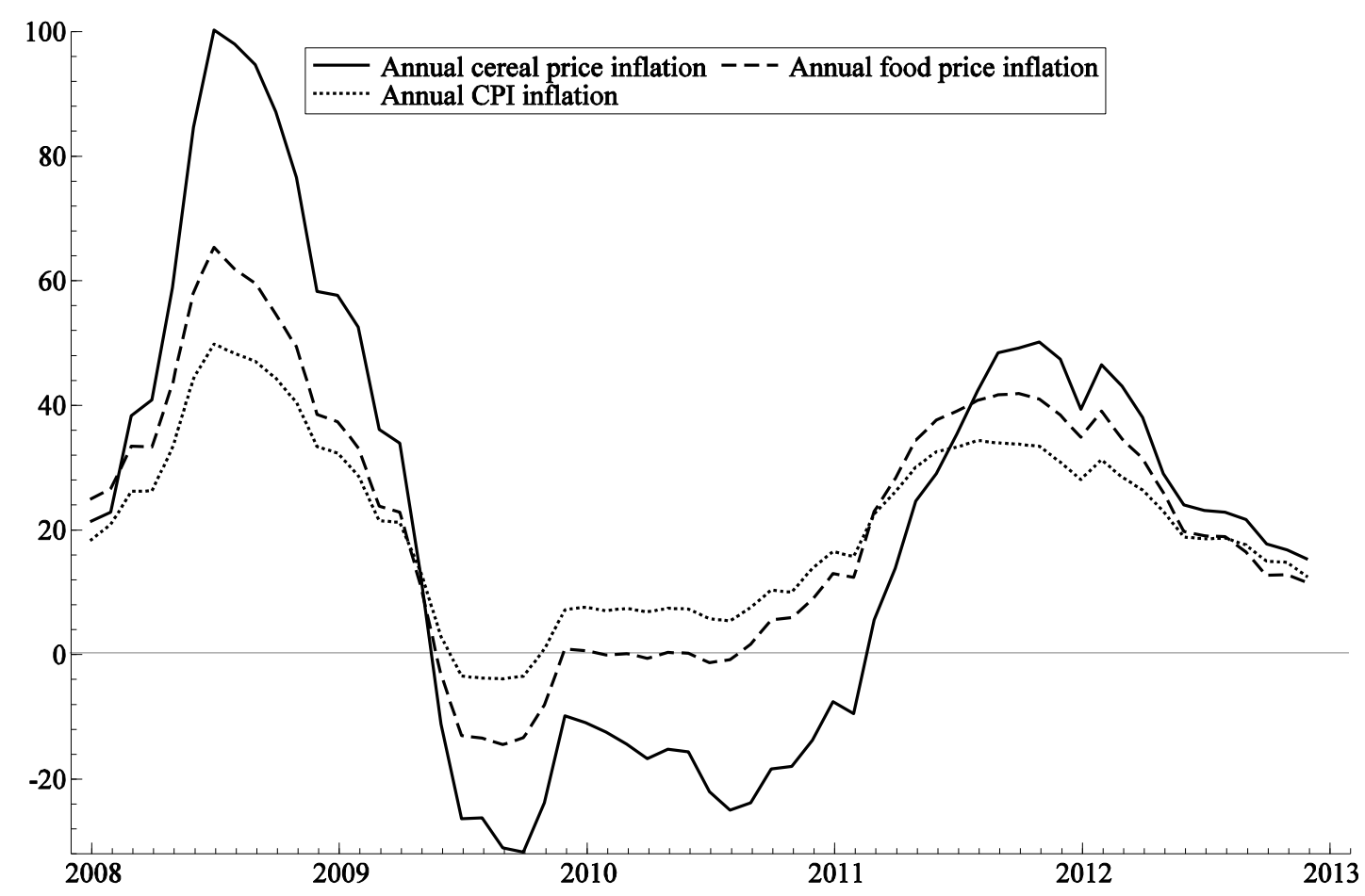

Figure 16: Annual cereal price and world grain price inflation, January 2008-December 2012.

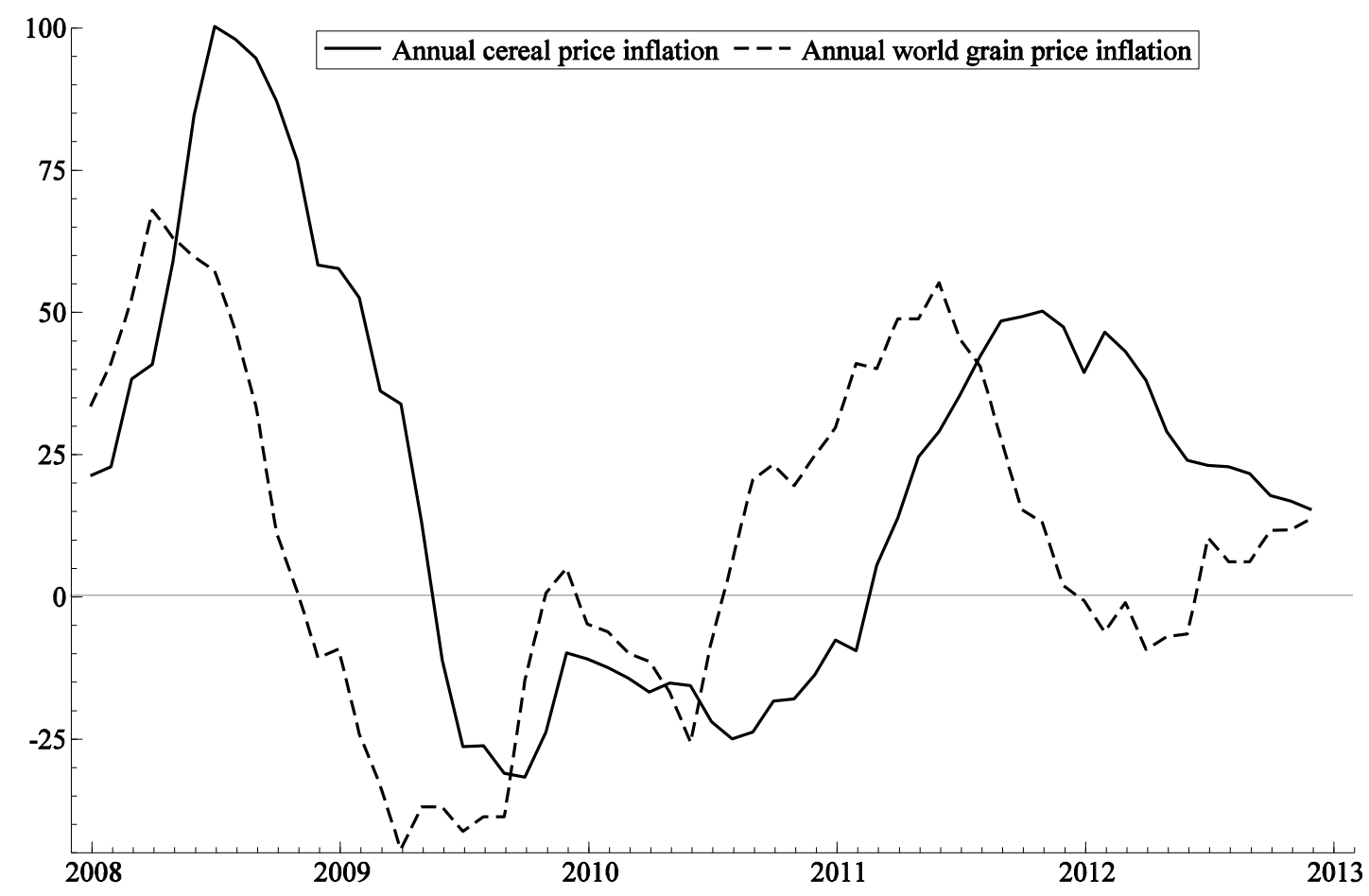


Figure 17: One-step forecasts of annual cereal price inflation, actual values, and $95 \%$ error bands.

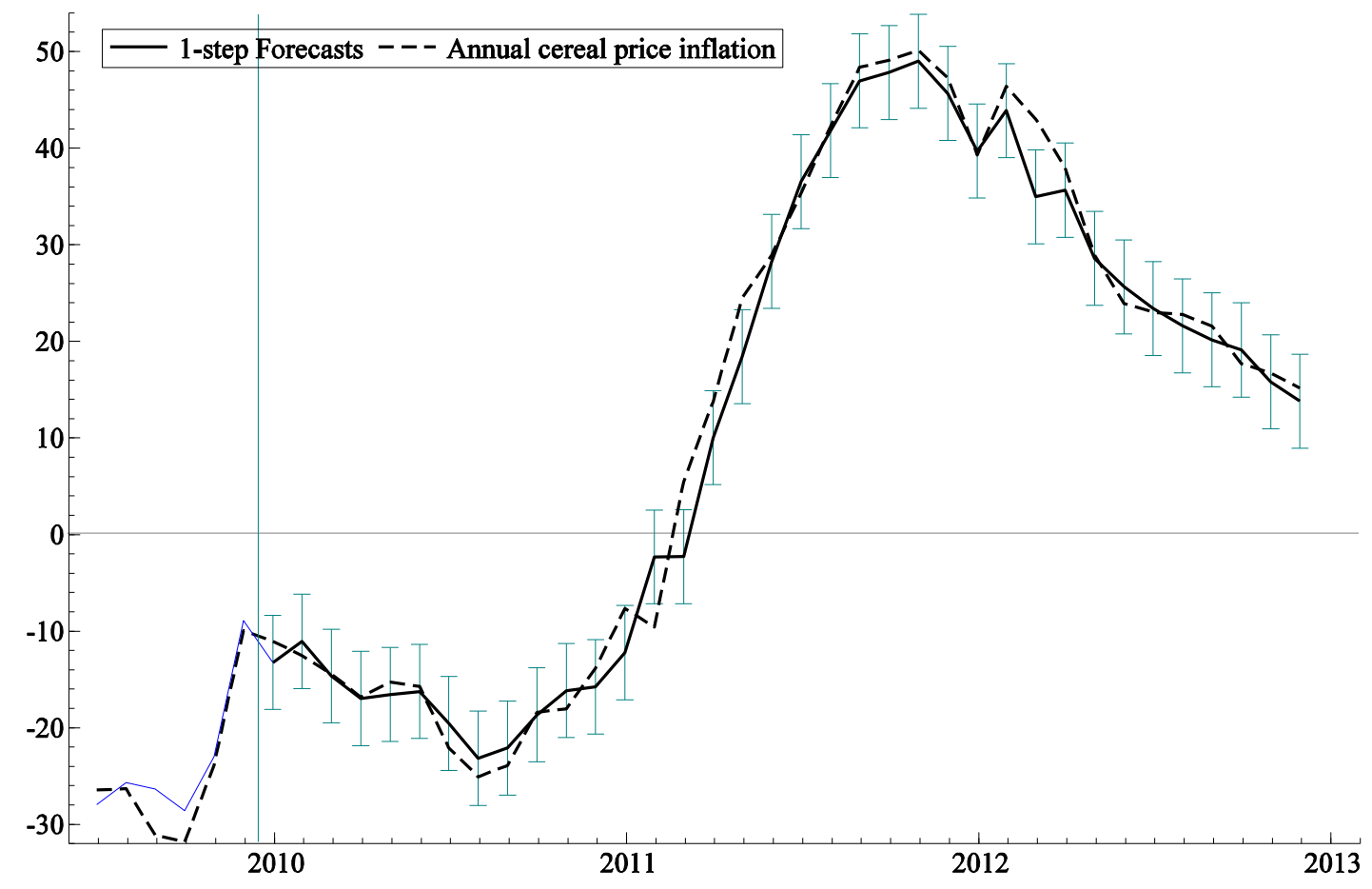

